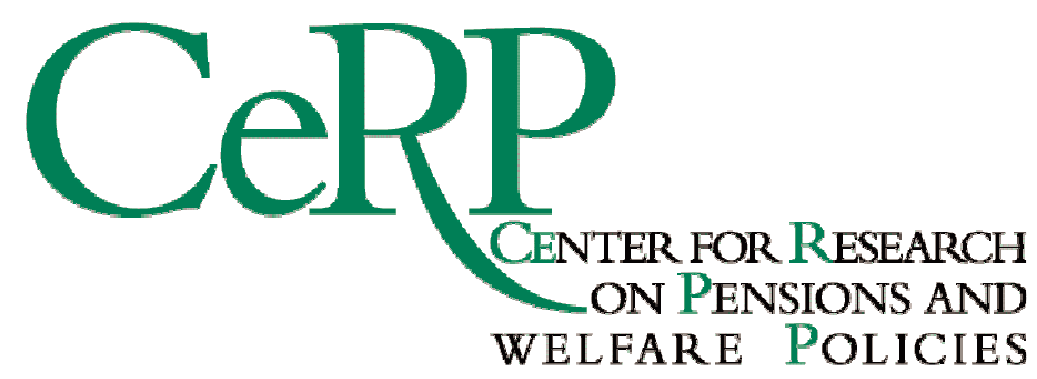

Working Paper 157/16

TO TRUST IS GOOD, BUT TO CONTROL IS BETTER: HOW INVESTORS DISCIPLINE FINANCIAL ADVISORS'ACTIVITY

Riccardo Calcagno

Maela Giofré

Maria Cesira Urzì-Brancati 


\title{
To trust is good, but to control is better: How investors discipline financial advisors' activity*
}

\author{
Riccardo Calcagno ${ }^{\dagger}$ Maela Giofréł Maria Cesira Urzì-Brancati ${ }^{\S}$ \\ EMLYON Business School, University of Turin, CeRP-Collegio Carlo Alberto, International Longevity Centre - UK
}

First draft: April 2015. This draft: March 2016

\begin{abstract}
Using a survey of clients from one of the largest Italian banks, we investigate whether investors exert some form of control over the quality of the recommendations they receive, and, if so, which one. We find that investors with low levels of trust seek financial counselling, but make their decisions autonomously. Within this subgroup of investors, those with high self-assessed financial competence are more likely to control the quality of the advice. We also observe that their test-based degree of financial literacy affects the way they discipline the advisors. Investors with high financial literacy monitor the advisors' activity themselves. Investors with low financial literacy, however, are more likely to seek a second expert's opinion that confirms the recommendations previously received, such as in the case of credence services. Our findings suggest that access to different financial institutions is especially beneficial for investors with poor financial literacy.
\end{abstract}

Keywords: Financial advice, Financial literacy, Credence services

JEL Classifications: G11, G24, D80

\footnotetext{
${ }^{*}$ We thank Annamaria Lusardi, Chiara Monticone, and seminar participants at the Cherry Blossom Financial Education Spring Institute (George Washington School of Business, April 2015), SKEMA Business School (Lille, October 2014) for helpful comments and discussions. Moreover, we also thank Laura Marzorati at Pioneer Investments for providing access to the Unicredit Customers Survey. We kindly acknowledge financial support from the European Commission through the Seventh Framework Programme for the project 'Mobilising the Potential of Active Ageing in Europe'.

${ }^{\dagger}$ EMYLON Business School and CeRP-Collegio Carlo Alberto; e-mail: calcagno@em-lyon.com

${ }^{\ddagger}$ University of Turin and CeRP-Collegio Carlo Alberto; email: maela.giofre@unito.it

${ }^{\S}$ ILC-UK (International Longevity Centre - UK); email: CesiraUrziBrancati@ilcuk.org.uk
} 


\section{Introduction}

Investors are being confronted with increasingly complex financial decisions, partly because shifting economic policies have forced them to take on more responsibilities and partly because the menu of retail financial products has been growing steadily. This poses a serious challenge to investors who want to buy the best possible financial product, given their lifetime needs. Several authors (Georgarakos and Inderst, 2011; Inderst and Ottaviani, 2012a,c) argue that the optimal financial choice depends on investor-specific need and personal characteristics. For example, the best real estate mortgage or the optimal pension scheme or investment plan depend, respectively, on the client's expected income stream, desired level of well-being at retirement, risk attitude, or tax bracket. In accordance to this view, financial advice can be considered as a credence service similar to medicine, where "money doctors help investors to get the most appropriate treatment" (Gennaioli et al., 2015, p.92). As for medical treatments, the accuracy of the expert in solving the client problem is not observable, the final success of the service is not contractible, and the expert's effort is costly, so that the investor-advisor relation is affected by moral hazard (Pesendorfer and Wolinsky, 2003; Fong, 2005; Dulleck and Kerchmbamer, 2006). Hence, investors who rely on professional financial advice either do so because they trust their advisors, as for Gennaioli et al. (2015), or because, despite anticipating a conflict of interest with the advisor, they are ready to control the quality of the recommendations they receive.

This paper studies whether investors exert some form of control over the quality of the recommendations they receive. If this is the case, we check how their degree of financial knowledge affects the control mechanism they enact.

For this purpose, we use the 2007 Unicredit Investors Survey (UCS) conducted on a sample of 1,676 individuals with a current account in one of the banks of the largest Italian banking group. We find that, irrespective of their level of financial education, investors with high trust in their advisors fully delegate them their financial decisions, as predicted by Gennaioli et al. (2015).

In our dataset, however, a large fraction of investors who demand professional advice do not delegate but make decisions autonomously after having received professional recommendations. These investors show a lower level of trust in their advisors than those who fully delegate their investment decisions. The main purpose of our paper is to investigate whether, among these investors, those with higher financial literacy are more likely to exert some form of control over advisor activity. Moreover, we try to assess whether their 
financial literacy affects the form of control they put in place. Pesendorfer and Wolinsky (2003) consider the search for second professional opinions as the most appropriate disciplining mechanism for standard credence goods such as medical advice. Unlike in medical counselling, financially educated investors when confronted with financial advice could try to verify the accuracy of the expert's recommendation by themselves. The monitoring costs are probably lower for investors with higher financial competence.

We show that the self-assessed level of financial competence is strongly related to some form of control activity: Investors who are more confident in their own financial knowledge are more likely to check the quality of advisors' recommendations.

We also find strong evidence that investors with the highest level of test-based financial literacy exert a direct form of control on advisor activity. Instead, investors with the lowest level of financial literacy are more likely to compare the recommendations they receive with second opinions, as postulated by Pesendorfer and Wolinsky (2003) for standard credence services. These results are robust if we take into account the potential endogeneity of both the level of trust in advisors and the degree of financial literacy.

We believe that identifying the mechanism of control put in place by wary investors, that is, investors who are aware of the agency bias of experts, is important to protect investors effectively. Given that investors with a low degree of financial literacy are more likely to seek second opinions, we can deduce that they may rationally not seek for advice if the search cost is too high. We suggest that policy interventions facilitating access to experts other than an investor's own bank advisor could benefit low-trust and unsophisticated investors, enabling them to identify economically sound advice more easily.

Our findings could also help to interpret some results in the literature. For example, they are consistent with those of Bhattacharya et al. (2012), who report that investors with low trust in the advisors and a low level of financial sophistication are less likely to seek professional advice, even when it is unbiased. According to the credence service view adopted in this paper, investors with low confidence in financial experts probably do not believe they are being offered unbiased recommendations. Therefore, they decide to seek advice only if they believe themselves to be competent enough to verify its quality.

The remainder of this paper is structured as follows. Section 2 describes the related literature. Section 3 reports the empirical analysis. Section 4 concludes the paper. 


\section{Related literature}

Inderst and Ottaviani (2012b) argue that, in many important financial decisions, the value realized by an investor operating a financial transaction depends on the match between the investor's needs and the characteristics of the product he has selected and only a professional advisor is able to identify the correct match. These characteristics are specific to credence goods, which are 'goods and services where an expert knows more about the quality a consumer needs than the consumer himself' (Dulleck and Kerchmbamer, 2006, p.5). The credence goods approach is not new in the industrial organization literature (Wolinski, 1993, 1997; Fong, 2005). ${ }^{1}$ In finance, Gennaioli et al. (2015) explicitly refer to financial advice as a credence service through which professionals guide investors with little knowledge in the acquisition of risky assets. The authors argue that investors delegate their risky investments to the advisor they trust the most because they are less anxious to take risks if they are counselled to do so than on their own, just as patients follow the treatment prescribed by a doctor they trust. Other works also highlight the positive effect of trust on stock market participation, as, for example, Guiso et al. (2008) and Georgarakos and Inderst (2011), especially for households with low financial capability. A peculiar characteristic of the model of Gennaioli et al. (2015) is that an investor with high trust in an advisor dismisses the latter's agency bias (Inderst and Ottaviani, 2012a,b), his incentive to sell products with higher fees (von Gaudecker, 2015), or even his incentive to mis-sell products (Inderst and Ottaviani, 2009).

We conjecture that investors with low confidence in their advisor could instead rationally anticipate the potential conflict of interest in the client-expert relation and exert some form of costly monitoring to overcome it. ${ }^{2}$ Considering the case of clients aware of the moral hazard inherent in credence services, Pesendorfer and Wolinsky (2003) study the effects of a mechanism that allows them to discipline it, that is, the search for a second opinion. Alternatively, an investor could verify the quality of the advisor's recommendation by paying monitoring costs.

Our work aims to contribute to the vast literature studying the determinants of the demand for professional advice. ${ }^{3}$ Some papers argue that the investor level of financial literacy explains the demand for advice. Using the 2009 Financial Industry Regulatory Authority (FINRA) Financial Capability Survey,

\footnotetext{
${ }^{1}$ For an exceptionally comprehensive review, see Dulleck and Kerchmbamer (2006).

${ }^{2}$ With reference to the mortgage market, Woodward and Hall (2000) emphasize that mortgage loans are leading examples of transactions where experts on one side of the market take advantage of consumers' lack of knowledge and experience. The authors find that confused borrowers overpay for brokers' services and that borrowers sacrifice at least $\$ 1,000$ due to shopping from too few brokers.

${ }^{3}$ See Hoikwang et al. (2016) for a study on the optimal delegation of investment management in a life cycle setting.
} 
Collins (2012) finds that more knowledgeable investors are more likely to seek financial advice than those with lower financial literacy. This same result is confirmed by van Rooij et al. (2011), Bucher-Koenen and Koenen (2011), and Calcagno and Monticone (2015) using different datasets. Instead, Georgarakos and Inderst (2011) find that investors who choose to participate in the stock market rely on advice only if their own level of financial education is sufficiently low. In addition, Hung and Yoong (2013) support the idea that demand for professional advice could substitute for the level of financial knowledge, while Hacketal et al. (2012) suggest that financial advisors are matched with wealthier and higher income households. We add to this literature by showing that investors asking for advice discipline their advisors differently according to their level of financial literacy: Investors with the highest financial literacy control by themselves the quality of the recommendations they receive. The least financially literate are more likely to seek a second opinion.

Several papers have documented that investors do not follow advice even when it has been certified as unbiased. Bhattacharya et al. (2012) highlight that the mere availability of unbiased financial advice is a necessary but not sufficient condition for benefiting retail investors. The authors find that investors who lack financial sophistication and trust are less likely to seek advice, even when it is unbiased and offered for free. Instead, Hacketal et al. (2010) analyse investor decisions to follow a recommendation that is truthfully certified as unbiased. Studying the trading behaviour of the retail clients of a German brokerage firm, the authors show that the greater the investor's financial knowledge and perception of conflicts of interest, the less likely the investor is to follow the expert's advice. This result is also confirmed by Stolper and Walter (2015) regarding basic retirement choices and the insurance of major life risks. Our findings suggest that, if investors do not trust experts and lack a credible control mechanism, they may not ask for advice in the first place.

\section{Empirical analysis}

The empirical analysis relies on the 2007 UCS, which draws from the population of clients of one of the three largest European banking groups. ${ }^{4}$ The 2007 wave interviewed 1,676 individuals with a current account in one of the banks of the Unicredit Group based in Italy. ${ }^{5}$ The UCS goal is to study retail customers' financial

\footnotetext{
${ }^{4}$ The UCS survey was repeated in 2009, but it then contained only a very limited number of questions, mostly concerning the respondents' degree of risk aversion. Therefore, we could not exploit this last wave for our purposes. By comparing the 2007 and 2009 waves, Guiso et al. (2013) find that risk aversion increased substantially after the financial crisis of 2008.

${ }^{5}$ The sample consists of clients in the age group 21-75 years, holding a current account and at least 10,000 euros.
} 
behaviour and their expectations towards the bank. The survey provides detailed information on households demographic structure, labour market position, individual financial assets holding (both within and outside the bank), and income. ${ }^{6}$ Furthermore, the survey contains data on the attitudes towards saving, financial investment, risk propensity and, more importantly for our purposes, it collects information on the degree of financial literacy of households and their relation with banks and financial advisors. In particular, the survey explicitly measures the degree of trust of the respondent in his financial advisor, and the nature and frequency of this relationship. Table 1 reports the main descriptive statistics of the variables considered in the analysis.

\section{(Insert Table 1 approximately here)}

The sample selected for our analysis includes only account holders who report that Unicredit is their main or only bank, leaving us with 1,581 observations.

The degree of trust in advisors is obtained from the answer to a specific question, which is reported in Appendix A. The financial literacy measure is constructed as for Guiso and Jappelli (2009) and Calcagno and Monticone (2015): it is related to the correct answer to eight questions regarding inflation, interest rate compounding, risk diversification, and products' riskiness. The overall distribution of the correct answers is shown in Fig. 1. The measure of self-assessed financial knowledge is equal to the self-reported ability to manage financial investment (on a scale of one to five) relative to the average. Lusardi and Mitchell (2014) report that there is often substantial mismatch between individuals' self-assessed knowledge and their actual knowledge. More specifically, Guiso and Jappelli (2009) find that these two measures are only weakly related in the UCS sample and can therefore have independent predictive power. The survey also provides information about other characteristics of the investor-advisor relationship crucial for our analysis: whether the investor asks for products sold by other financial intermediaries (a proxy for the search for second opinion), how often the investor asks information to his advisor (a proxy for the monitoring behaviour) and which factors are driving the investor's choice of bank. A precise description of all the variables can be found in Appendix A.

\footnotetext{
${ }^{6}$ As illustrated by Guiso and Jappelli (2009), the individuals in the UCS sample are older and wealthier than in the Bank of Italy's Survey on Household Income and Wealth (SHIW) study which is representative of the whole Italian population.
} 


\subsection{Preliminary results: The effects of trust}

The UCS contains information about the way individuals manage their financial investment, that is, whether they decide autonomously (Self), ask for advisor counselling but decide independently (Advice), or fully delegate their choice to the advisor (Delegation). In Table 2, we report the percentages of investors falling in these three categories, as well as for the subsample of those holding risky assets. The fraction of investors asking for advice but deciding independently is the largest, ranging from $48 \%$ in the full sample to $69 \%$ for investors holding risky assets.

(Insert Table 2 approximately here)

From Table 2 one can see that the higher the level of trust in the advisor, the more likely the investor fully delegates his choice to the latter. This preliminary evidence supports the model of Gennaioli et al. (2015), who argue that investors who unconditionally trust their advisor fully delegate their financial decisions, exactly as a patients delegate the care of their health to a doctor they trust.

The level of trust could be correlated with other variables influencing the way investors make their decisions. Therefore, we investigate the effect of trust in a multivariate regression setting. Given that the UCS asks only respondents who hold risky assets how these investors manage their decisions, we estimate an ordered probit model with sample selection. Table 3 presents the results of our regression.

(Insert Table 3 approximately here)

In column (1) of Table 3, we report the estimates of a probit model in which investors either hold risky assets or do not. We use the level of risk aversion as exclusion restriction here. More risk-averse investors are less likely to hold risky assets, as expected. The results again confirm the predictions of Gennaioli et al. (2015): Investors who trust their advisors more are more likely to invest in risky assets. In addition, the test-based level of financial literacy has a strong positive impact on holding risky assets, as shown in the literature (Guiso and Jappelli, 2009; van Rooij et al., 2011; Clark et al., 2016), as does the measure of self-assessed financial capability.

In columns (2a) to (2c) of Table 3, we present the effects of trust, test-based financial literacy, and selfassessed financial competence on the way investors use professional counselling. We run a Heckman ordered probit model in which the dependent variable is, respectively, Self (column (2a)), Advice (column (2b)), or Delegation (column (2c)). The level of trust increases the probability of full delegation, as predicted 
by Gennaioli et al. (2015), while it decreases the probabilities of both asking for advice and investing autonomously: Specifically, the effect of trust appears to be stronger in the choice to invest autonomously than in the choice to ask for advice. While both financial literacy and self-assessed financial knowledge drive the choice to hold risky assets, only the latter appears to have a significant impact on the choice to rely on professional advice.

To address the potential endogeneity of trust and financial literacy with respect to investor choice, we report in columns (3) and (4a) to (4c) of Table 3 the instrumented version of the previous model. ${ }^{7}$ Dealing with probit or ordered probit models, we adopt the control function approach, that is, a two-stage residual inclusion (2SRI) estimation, as described by Wooldridge (2010). ${ }^{8}$ We instrument the level of trust in advisors with two variables capturing the general level of trust. ${ }^{9}$ To instrument financial literacy, we adopt instead the regional level of financial literacy derived from the Bank of Italy's SHIW and a dummy variable indicating whether the head of household was in the group of best students when attending school at ages 11-14. Also this instrumented version of the ordered probit model confirms the positive role of trust in the choice to fully delegate. ${ }^{10,11}$

\subsection{The control activity of investors asking for advice}

Table 2 shows that more than $68 \%$ of the investors who hold risky assets regularly consult their advisor but decide autonomously how to invest (Advice). They trust professional counselling significantly less than investors who fully delegate their decisions do. It is plausible to assume that at least part of investors choosing Advice are aware that the recommendations they receive can be biased (Woodward and Hall, 2012; Inderst and Ottaviani, 2009, 2012c). These wary investors are likely to discipline their advisors' activity. After verifying some of the hypothesis put forward in the literature, we provide the original contribution of this paper, that is, the identification of the disciplining mechanism investors enact to control the quality of

\footnotetext{
${ }^{7}$ The instrumental variable approach is implemented in the selection equation, since the Wu-Hausman test of endogeneity rejects the hypothesis of exogeneity of the two (potentially endogenous) regressors in the selection equation $(p$-value $=0.00)$, but not in the outcome equation $(p$-value $=0.12)$.

${ }^{8}$ Since the fitted residuals from the first-stage are included in the second stage-regression as a additional regressors, the standard errors need to be corrected (Wooldridge, 2010, pp.126-129). Standard error correction is achieved by bootstrapping the relevant equation estimation.

${ }^{9}$ See Appendix A for further details on the instruments.

${ }^{10}$ Note that the number of observations for the instrumented version of the selection and outcome equations drops from 1,581 and 1,116 to 1,550 and 1,098, respectively. This is due to missing observations (31 in the full sample, 18 in the selected sample) after instrumenting individuals' financial literacy with the average regional financial level in the SHIW dataset (it being impossible to associate any Italian birth region for clients born abroad).

${ }^{11}$ Since the system of equations is over-identified, we report at the bottom of Table 3 standard test statistics that confirm the validity of the adopted instruments.
} 
the recommendations they receive.

Given the similarities between financial advice and a credence service suggested by Gennaioli et al. (2015), we refer to Pesendorfer and Wolinsky (2003) to predict the behaviour of wary investors asking for advice. Pesendorfer and Wolinsky (2003) present a model of standard credence goods where clients can discipline an expert's activity only by seeking a second professional opinion that confirms the recommendation previously received. For standard credence services such as medical advice, the cost of checking whether the doctor's recommendation is correct is too high for patients. This cost is likely to be similar across patients endowed with different levels of education, except for those who studied medicine. Instead, for a service such as financial advice, the degree of investor competence could play a role in the strategic interaction between advisor and client (Collins, 2012; van Rooij et al., 2011; Hung and Yoong, 2013). More financially educated investors are better able to find good advisors, to understand better the characteristics of the advised portfolios, and generally pay lower costs in evaluating a recommendation. These investors can verify the accuracy of the advisor's choice by directly monitoring the expert's activity at a cost that decreases with the investor's financial literacy. For this reason, we conjecture that more financially literate investors control advisors by directly monitoring their activity, while less literate investors might seek a second opinion, as for Pesendorfer and Wolinsky (2003).

\subsubsection{Direct monitoring and investor competence}

To properly test this conjecture, we first need to carry out a further selection step among investors holding risky assets to exclude those who invest without any professional counselling. We build on the model of Pesendorfer and Wolinsky (2003) and construct a measure proxying for the expected payoff the investor earns by referring to a professional advisor. While the expected benefit of seeking advice is proportional to the quality of the advice, the disciplining cost depends on the investor's cost to control advisor activity. A rational investor asks for advice only if the expected benefit of doing so exceeds the expected cost. Hence we should observe that investors obtaining lower benefits from advice or paying higher control costs are less likely to ask for advice. We measure the net benefit of asking for advice with the variable Expected payoff of advice/delegate. ${ }^{12}$

In Table 4, we perform a Heckman probit regression with double sample selection. In the first column, we report the result of the first sample selection, which restricts to investors holding risky assets. Column (2)

\footnotetext{
${ }^{12}$ See Appendix A, for details on the construction of this measure.
} 
shows the results of the second selection equation, which identifies investors who ask for financial counselling. The exclusion restriction adopted in the second selection is precisely the Expected payoff of advice/delegate: The larger this payoff, the more likely the investor asks for financial advice. Indeed, we find that this measure is statistically significant (coeff. $=0.070)$ to explain the choice of investors asking for advice or to delegating. The level of trust also has a very strong, positive effect on this decision.

\section{[Insert Table 4 approximately here]}

We then test against the data our main hypothesis, that is, whether the degree of financial competence has an impact on the investor's monitoring behaviour. As a proxy measure of direct monitoring, we use a binary measure of the frequency of meetings between investors and their advisors. ${ }^{13}$ As explained above, we expect more financially competent investors to be likely to monitor advisor activity more closely.

In columns (3) to (5) of Table 4, we report our findings. The (\#a) columns refer to the overall selected sample (Advice or Delegation), while the (\#b) columns refer to the subsample of investors asking advice but deciding autonomously (Advice). We observe that, in both the (\#a) and (\#b) specifications, the test-based and self-assessed measures of financial literacy increase the probability of monitoring the advisor. The two coefficients are, respectively, 0.018 and 0.039 in column (3a) and 0.019 and 0.074 in column (3b).

To further investigate the different behaviours of investors belonging to different segments of the financial literacy distribution, in columns (4a) to (4b) of Table 4, we study those belonging to the upper part of the distribution. ${ }^{14}$ We consider the dummy variable Financial Literacy_high equal to one for those investors scoring at least six out of eight correct answers, representing approximately the highest $10 \%$ of the distribution, and zero otherwise. We find that investors in the highest percentiles of the distribution are more likely to monitor their advisors (coeff. $=0.060)$, in both the subsample of those asking advice/delegation (column (4a)) and in the subsample of those asking pure advice (column (4b)). The latter display a stronger self-confidence (0.078 versus 0.040$)$.

Finally, in columns (5a) to (5b) of Table 4, we specifically test the behaviours of highly literate versus lowly literate investors. We therefore also include the dummy variable Financial Literacy_medium, equal to one if the investors score four (median) or five out of eight correct answers, and zero otherwise. The

\footnotetext{
${ }^{13}$ See Appendix A, for a precise definition of the proxy for monitoring.

${ }^{14}$ In Figures 1 and 2, we plot the frequency and cumulative distribution functions, respectively, of the variable Financial Literacy. Since the variable is discrete, we are not allowed to choose any desired percentile level. In Section 3.3, we also discuss findings relying on alternative measures of financial literacy, also to dispel doubt about the financial literacy percentiles used in the main specification.
} 
results confirm that highly literate investors are more likely to monitor advisor activity than those with low financial literacy (scoring zero to three): In the subsample of investors asking advice or delegating (column (5a)), both investors with high financial literacy and those with medium financial literacy are more likely to monitor advisors than poorly literate investors, with marginal effects equal to 0.011 and 0.061 , respectively. In the subsample of investors asking pure advice (column (5b)), highly literate investors are confirmed as more likely to monitor the advisor's activity $($ coeff. $=0.092)$, while we do not detect a significant difference in the behaviours of investors with medium and poor financial literacy.

\subsubsection{Second opinion and investor competence}

The results illustrated in the previous section suggest that investors with high financial literacy are more likely to monitor the activity of advisors by themselves. What about less literate investors? Do they exert any form of control? For investors with a lower degree of competence, financial advice could be considered a standard credence service for which a client can discipline the expert activity only by seeking a second opinion (Pesendorfer and Wolinsky, 2003). Our survey contains a binary question asking whether the respondent ever asked their bank about products managed by other banks or financial institutions. ${ }^{15}$ We interpret a positive answer to this question as a signal that the investor controls advisor behaviour through a comparison mechanism, similar to seeking a second opinion.

\section{[Insert Table 5 approximately here]}

In Table 5, we perform a Heckman probit regression with double sample selection. Analogously to Table 4, in columns (1) and (2), we simply report the results of the two selection equations, which are the same across the two tables, and, in columns (3) to (5), we report our findings. As before, the (\#a) columns refer to the overall selected sample (Advice or Delegation), while the $(\# \mathrm{~b})$ columns refer to the subsample of those asking advice and deciding autonomously (Advice). As for monitoring, columns (3a) and (3b) of Table 5 show that a high level of self-assessed financial knowledge increases the probability of seeking a second opinion. Putting together these results, we find a positive correlation between the degree of financial self-confidence and the probability of exerting control over one's advisor.

The sign of the coefficient of the test-based measure of financial literacy, though not statistically different from zero, becomes negative when we focus on the subsample asking for advice (column (3b) of Table 5).

\footnotetext{
${ }^{15}$ See Appendix A, for details on the construction of this measure.
} 
This suggests that a lower level of financial literacy could be associated with a more intense search for a second opinion. To test this conjecture, we replicate the previous analysis considering only investors with the lowest level of financial literacy. In columns (4a) to (4b) of Table 5, we introduce the dummy variable Financial Literacy_low, which equals one for investors scoring at most three out of eight correct answers, representing approximately the lowest $20 \%$ of the selected subsample, and zero otherwise. Interestingly, if we restrict the analysis to the subsample asking for advice (column (4b)), we see that investors at the bottom of the distribution of financial literacy are more likely to control their advisor by seeking a second opinion (coeff: $=0.085)$. This finding corroborates the credence service view espoused in the paper: only investors who ask for advice but choose autonomously seek a second opinion to discipline the advisor's activity. In columns (5a) and (5b) of Table 5, finally, we specifically test the behaviours of lowly literate versus highly literate investors by adding the dummy variable Financial Literacy_medium, defined as above. Again, (only) when looking at investors asking for advice (column (5b)), we find that a low degree of financial literacy significantly increases the probability of seeking a second opinion (coeff. $=0.072$ ). Poorly literate investors are more likely to seek a second opinion than highly literate investors are, while investors endowed with a medium financial literacy display no difference with respect to more knowledgeable investors.

To conclude, the findings in Tables 4 and 5 suggest that, among investors who ask for advice but decide autonomously, those more confident in their own financial knowledge exert some form of control over the advisor activity. Moreover, those at the top of the distribution of the test-based financial literacy distribution discipline their advisors through direct monitoring, while those at the bottom control their advisors' behaviour by comparing different recommendations. It is therefore crucial for the latter to have access to many different experts at low cost in order to identify the economically sound advice.

\subsection{Robustness}

This section presents a series of additional analyses that verify the robustness of our findings to different specifications of the main variables. We check the robustness of the results illustrated in the previous section to the definition of our two main regressors, namely, Trust in advisor and (test-based) Financial Literacy. ${ }^{16}$

Table 3a reports the robustness results of Table 3. Here we replace the variable Trust in advisor taking

\footnotetext{
${ }^{16}$ Tables $6 \mathrm{a}, 6 \mathrm{~b}$, and $6 \mathrm{c}$ report additional robustness results for the second selection equation of Tables 4 and 5 . Tables $6 \mathrm{a}$ and $6 \mathrm{~b}$ report findings under two alternative specifications of the exclusion restriction, that is, the measure Expected payoff of advice/delegate (see Appendix A for details), while Table 6c shows the results under the alternative specification of trust. All three tables deliver results qualitatively similar to those in columns (1) and (2) of Tables 4 and 5.
} 
the values one to five with the binary variable Trust in advisor_ 1 . The effect of trust is further reinforced, pointing to a robust correlation between trust and delegation.

Tables $4 \mathrm{a}$ and $4 \mathrm{~b}$ report the robustness results of Table 4 when the variable Financial Literacy is replaced by two alternative specifications of the same variable -Financial Literacy_1 and Financial Literacy_2obtained after excluding the question that recorded, respectively, the highest and lowest scores for the corrected answers' results, as detailed in Appendix A. ${ }^{17}$ The main findings of Table 4 persist: Investors with a high level of financial literacy are more likely to monitor advisor behaviour than investors with low and medium financial literacy.

Analogously, Tables $5 \mathrm{a}$ and $5 \mathrm{~b}$ report the robustness results of Table 5 when the outcome variable considered is Second opinion rather than Monitoring. In addition, under these alternative specifications of financial literacy, the results from the baseline specification are confirmed: Investors at the bottom of the financial literacy distribution are more likely to ask for a second opinion to verify previously received recommendations. ${ }^{18}$

\section{Conclusions}

This paper empirically investigates whether investors exert some form of control over the quality of the recommendations they receive and, if so, which mechanism they choose.

As predicted by Gennaioli et al. (2015), we find that, irrespective of their level of financial education, investors with high trust in their advisors are more likely to fully delegate their financial decisions. A large fraction of investors seeks financial counselling but makes decisions autonomously. If we restrict our analysis to these latter investors, we observe that those with greater self-confidence in their ability to understand finance problems are more likely to exert some form of control over their advisors. The degree of testbased financial literacy influences the control mechanism the investor enacts. Investors with the highest level of financial literacy verify the accuracy of expert recommendations directly. Investors with the lowest level of financial literacy instead seek a second expert opinion that confirms the recommendation previously

\footnotetext{
${ }^{17}$ Figures $1 \mathrm{a}, 1 \mathrm{~b}, 2 \mathrm{a}$, and $2 \mathrm{~b}$ plot the frequency distribution and the cumulative distribution functions of the two alternative measures of Financial Literacy.

${ }^{18}$ Table 5b shows that, as far as the investors seeking pure advice are concerned (columns (\#b)), the coefficient of Financial Literacy_2_low is statistically significant against the excluded categories of medium and high financial literacy investors (column (4b)), while it is (only marginally) non significant $(p$-value $=0.105)$ against the excluded category of highly literate investors (column (5b)). This same result holds also when the medium level of Financial literacy is included (column (5b)). This result emphasizes that investors with low financial literacy are significantly more likely to seek second opinion than investors with medium financial literacy.
} 
received. This latter control mechanism suggests that, for financially illiterate investors, financial advice can be considered a credence service, as for Pesendorfer and Wolinsky (2003). Our results then suggest then that easy access to several different experts' opinions can be particularly beneficial for the least financially educated investors. 


\section{References}

Bhattacharya, U., A. Hackethal, S. Kaesler, B. Loos, and S. Meyer (2012). Is unbiased financial advice to retail investors sufficient? answers from a large field study. Review of Financial Studies 25, 975-1032.

Bucher-Koenen, T. and J. Koenen (2011). Do smarter consumers get better advice? an analytical framework and evidence from private pensions. CDSE Discussion Paper 105.

Calcagno, R. and C. Monticone (2015). Financial literacy and the demand for financial advice. Journal of Banking and Finance 50, 363-380.

Clark, R., A. Lusardi, and O. Mitchell (2016). Financial knowledge and 401(k) investment performance: a case study. Journal of Pension Economics and Finance forthcoming.

Collins, J. (2012). Financial advice: a substitute for financial literacy? Financial Services Review 21, $307-322$.

Dulleck, U. and R. Kerchmbamer (2006). On doctors, mechanics, and computer specialists: the economics of credence goods. Journal of Economic Literature 44, 5-42.

Fong, Y. (2005). When do experts cheat and whom do they target? Rand Journal of Economics 36, $113-130$.

Gennaioli, N., A. Shleifer, and R. Vishny (2015). Money doctors. Journal of Finance 70, 91-114.

Georgarakos, D. and G. Inderst (2011). Financial advice and stock market participation. ECB Working Paper Series No. 1296.

Guiso, L. and T. Jappelli (2009). Financial literacy and portfolio diversification. CSEF Working Papers 212.

Guiso, L., P.Sapienza, and L. Zingales (2008). Trusting the stock market. Journal of Finance 63(6).

Guiso, L., P.Sapienza, and L. Zingales (2013). Time varying risk aversion. NBER Working Papers 19284.

Hacketal, A., M. Haliassos, and T. Jappelli (2012). Financial advisors: A case of babysitters? Journal of Banking and Finance 36, 509-524.

Hacketal, A., R. Inderst, and S. Meyer (2010). Trading on advice. CEPR Discussion Paper DP8091.

Hoikwang, H., R. Maurer, and O. Mitchell (2016). Time is money: Rational life cycle inertia and the delegation of investment management. Journal of Financial Economics forthcoming.

Hung, A. and J. Yoong (2013). Asking for help: Survey and experimental evidence on financial advice and behavior change. in O. Mitchell and K. Smetters, The Market for Retirement Financial Advice, Oxford University Press.

Inderst, R. and M. Ottaviani (2009). Misselling through agents. American Economic Review 99, 883-908.

Inderst, R. and M. Ottaviani (2012a). Competition through commissions and kickbacks. American Economic Review 102(2), 780-809.

Inderst, R. and M. Ottaviani (2012b). Financial advice. Journal of Economic Literature 50, 494-512.

Inderst, R. and M. Ottaviani (2012c). How (not) to pay for advice: A framework for consumer financial protection. Journal of Financial Economics 105(2), 393-411. 
Lusardi, A. and O. Mitchell (2014). The economic importance of financial literacy: Theory and evidence. Journal of Economic Literature 52, 5-44.

Pesendorfer, W. and A. Wolinsky (2003). Second opinion and price competition: inefficiency in the market for expert advice. Review of Economic Studies 70, 417-437.

Stolper, O. and A. Walter (2015). It takes two to tango: Households' response to financial advice and the role of financial sophistication. Available at SSRN: http://ssrn.com/abstract=2670511 July.

van Rooij, M., A. Lusardi, and R. Alessie (2011). Financial literacy and stock market participation. Journal of Financial Economics 101, 449-472.

von Gaudecker, H. (2015). How does household portfolio diversification vary with financial sophistication and advice? Journal of Finance 70(2), 489-507.

Wolinski, A. (1993). Competition in a market for informed experts' services. Rand Journal of Economics 24, 380-398.

Wolinski, A. (1997). Credence goods and fraudolent experts. Rand Journal of Economics 28, 107-119.

Woodward, S. and R. Hall (2000). Consumer confusion in the mortgage market: Evidence of less than a perfectly transparent and competitive market. American Economic Review: Papers and Proceedings 100, $511-515$.

Woodward, S. and R. Hall (2012). Diagnosis consumer confusion and sub-optimal shopping effort: Theory and mortgage-market evidence. American Economic Review 102, 3249-3276.

Wooldridge, J. (2010). Econometric analysis of cross section and panel data. 2nd Ed. MIT Press. Cambridge, Massachusetts. 


\section{Tables}

Table 1. Descriptive statistics

\begin{tabular}{|c|c|c|c|c|c|}
\hline Variable & Mean & Median & Std. dev & Min & Max \\
\hline \multicolumn{6}{|l|}{ Variables in main specification } \\
\hline Trust in advisor & 3.798 & 4 & 0.905 & 1 & 5 \\
\hline Financial Literacy & 4.658 & 5 & 1.476 & 0 & 8 \\
\hline Self-assessed financial knowledge & 2.877 & 2.9 & 0.846 & 1 & 5 \\
\hline Second Opinion & 0.062 & 0 & 0.241 & 0 & 1 \\
\hline Monitoring & 0.868 & 1 & 0.339 & 0 & 1 \\
\hline Risk aversion & 2.886 & 3 & 0.719 & 1 & 4 \\
\hline Expected payoff of advice/delegate & 0.674 & 1 & 0.469 & 0 & 1 \\
\hline Experience & 13.038 & 11 & 12.753 & 0 & 53 \\
\hline Finance sector & 0.034 & 0 & 0.180 & 0 & 1 \\
\hline Financial wealth: $10-50 \mathrm{k}$ & 0.183 & 0 & 0.387 & 0 & 1 \\
\hline Financial wealth: $50-100 \mathrm{k}$ & 0.232 & 0 & 0.422 & 0 & 1 \\
\hline Financial wealth: $100-150 \mathrm{k}$ & 0.201 & 0 & 0.401 & 0 & 1 \\
\hline Financial wealth: $150-250 \mathrm{k}$ & 0.175 & 0 & 0.380 & 0 & 1 \\
\hline Financial wealth: $250-500 \mathrm{k}$ & 0.157 & 0 & 0.364 & 0 & 1 \\
\hline Financial wealth: $>500 \mathrm{k}$ & 0.052 & 0 & 0.222 & 0 & 1 \\
\hline Individual income (euro) & 49946.560 & 31000 & 67933.000 & 200 & 822000 \\
\hline Female & 0.306 & 0 & 0.461 & 0 & 1 \\
\hline Age & 54.827 & 57 & 12.313 & 25 & 89 \\
\hline Years at school & 12.381 & 13 & 3.905 & 0 & 20 \\
\hline Retired & 0.336 & 0 & 0.473 & 0 & 1 \\
\hline Self-employed & 0.267 & 0 & 0.442 & 0 & 1 \\
\hline Years at Unicredit: $<1$ & 0.011 & 0 & 0.103 & 0 & 1 \\
\hline Years at Unicredit: 1-5 & 0.100 & 0 & 0.300 & 0 & 1 \\
\hline Years at Unicredit: 6-10 & 0.187 & 0 & 0.390 & 0 & 1 \\
\hline Years at Unicredit: $11-20$ & 0.236 & 0 & 0.425 & 0 & 1 \\
\hline Years at Unicredit: >20 & 0.466 & 0 & 0.499 & 0 & 1 \\
\hline North west & 0.221 & 0 & 0.415 & 0 & 1 \\
\hline North east & 0.288 & 0 & 0.453 & 0 & 1 \\
\hline Center & 0.243 & 0 & 0.429 & 0 & 1 \\
\hline South-Islands & 0.248 & 0 & 0.432 & 0 & 1 \\
\hline \multicolumn{6}{|l|}{ Variables in alternative specifications } \\
\hline Trust in advisor_1 & 0.729 & 1 & 0.444 & 0 & 1 \\
\hline Financial Literacy_1 & 4.143 & 4 & 1.353 & 0 & 7 \\
\hline Financial Literacy_2 & 4.530 & 5 & 1.417 & 0 & 7 \\
\hline Expected payoff of advice/delegate_1 & 0.194 & 0 & 0.395 & 0 & 1 \\
\hline Expected payoff of advice/delegate_2 & 0.690 & 1 & 0.463 & 0 & 1 \\
\hline \multicolumn{6}{|l|}{ Instruments } \\
\hline Regional Financial literacy (average) & 1.577 & 1.498 & 0.335 & 0.781 & 1.961 \\
\hline School performance & 0.166 & 0 & 0.373 & 0 & 1 \\
\hline Generalized trust_1 & 0.260 & 0 & 0.439 & 0 & 1 \\
\hline Generalized trust_2 & 4.187 & 4 & 0.853 & 1 & 5 \\
\hline
\end{tabular}

Source: UCS (2007) 
Table 2. Descriptive statistics on trust and demand for advice

\begin{tabular}{|c|c|c|c|c|c|}
\hline & \multirow{3}{*}{$\begin{array}{c}\text { Full sample } \\
\text { Percent }\end{array}$} & \multicolumn{4}{|c|}{ Sample holding risky assets } \\
\hline & & \multirow[b]{2}{*}{ Percent } & \multicolumn{3}{|c|}{ Trust in advisor } \\
\hline & & & Mean & Median & Std.dev \\
\hline \multicolumn{6}{|l|}{ Demand for advice } \\
\hline Self & 7.84 & 11.11 & 3.083 & 3 & 1.096 \\
\hline Advice & 48.39 & 68.55 & 3.884 & 4 & 0.787 \\
\hline Delegation & 14.36 & 20.34 & 4.282 & 4 & 0.719 \\
\hline Does not hold risky assets & 29.41 & & & & \\
\hline Total & 100 & 100 & & & \\
\hline \# observations & 1581 & \multicolumn{4}{|c|}{1116} \\
\hline
\end{tabular}

Source: UCS (2007) 


\section{Table 3. Demand for advice and trust}

This table reports the marginal effects on conditional probability of an ordered probit model with sample selection. Column (1) reports results of the selection equation Hold risky assets while columns (2a)-(2c) report results of the outcome equation SelfAdvice-Delegation estimated as a Heckman ordered probit model with sample selection. The endogenous regressors Financial Literacy and Trust in advisor are instrumented by Regional Financial literacy, School performance, Generalized Trust_ 1 and Generalized Trust_2 (see Appendix A for details on the variables). Consistently with the results of the Wu-Hausman test reported, the Instrumental Variable regression is implemented in the selection equation. Tests of instruments' validity are reported at the bottom of the table. Heteroskedasticity robust standard errors are reported in parentheses. ***, **, and * indicate significance at the 1,5 , and $10 \%$ levels, respectively.

\begin{tabular}{|c|c|c|c|c|c|c|c|c|}
\hline & \multicolumn{4}{|c|}{ Heckman ordered probit with selection } & \multicolumn{4}{|c|}{ Heckman ordered probit with selection (IV) } \\
\hline & $\begin{array}{l}\text { Selection } \\
\text { Hold risky assets }\end{array}$ & Self & Advice & Delegation & $\begin{array}{l}\text { Selection } \\
\text { Hold risky assets }\end{array}$ & Self & Advice & Delegation \\
\hline & (1) & (2a) & $(2 b)$ & (2c) & (3) & (4a) & $(4 b)$ & (4c) \\
\hline Trust in advisor & $\begin{array}{l}0.041{ }^{* * *} \\
(0.011)\end{array}$ & $\begin{array}{l}-0.089 * * * \\
(0.009)\end{array}$ & $\begin{array}{l}-0.053 * * * \\
(0.009)\end{array}$ & $\begin{array}{l}0.1422^{* * *} \\
(0.013)^{2 *}\end{array}$ & $\begin{array}{l}0.316 * * * \\
(0.063)\end{array}$ & $\begin{array}{l}-0.085 * * * \\
(0.009)\end{array}$ & $\begin{array}{l}-0.054 * * * \\
(0.009)\end{array}$ & $\begin{array}{l}0.1399^{* * *} \\
(0.013)^{*}\end{array}$ \\
\hline Financial Literacy & $\begin{array}{l}0.0422^{* * *} \\
(0.007)^{2}\end{array}$ & $\begin{array}{c}-0.001 \\
(0.006)\end{array}$ & $\begin{array}{c}-0.001 \\
(0.004)\end{array}$ & $\begin{array}{c}0.002 \\
(0.010)\end{array}$ & $\begin{array}{l}0.224{ }^{* * *} \\
(0.057)\end{array}$ & $\begin{array}{c}0.000 \\
(0.005)\end{array}$ & $\begin{array}{c}0.000 \\
(0.003)\end{array}$ & $\begin{array}{c}0.000 \\
(0.009)\end{array}$ \\
\hline Self-assessed financial knowledge & $\begin{array}{l}0.030 * * \\
(0.014)^{* *}\end{array}$ & $\begin{array}{l}0.0199^{* *} \\
(0.009)^{*}\end{array}$ & $\begin{array}{l}0.011 * \\
(0.006)\end{array}$ & $\begin{array}{l}-0.030^{* *} \\
(0.015)\end{array}$ & $\begin{array}{l}-0.051 * * \\
(0.026)\end{array}$ & $\begin{array}{l}0.021)^{* *} \\
(0.009)^{*}\end{array}$ & $\begin{array}{l}0.0144^{* *} \\
(0.006)^{*}\end{array}$ & $\begin{array}{l}-0.035 * * \\
(0.015)\end{array}$ \\
\hline Experience & $\begin{array}{l}0.007 \quad * * * \\
(0.001)^{*}\end{array}$ & $\begin{array}{c}-0.001 \\
(0.001)\end{array}$ & $\begin{array}{c}-0.001 \\
(0.001)\end{array}$ & $\begin{array}{c}0.002 \\
(0.001)\end{array}$ & $\begin{array}{c}0.002 \\
(0.002)\end{array}$ & $\begin{array}{c}-0.001 \\
(0.001)\end{array}$ & $\begin{array}{c}-0.001 \\
(0.000)\end{array}$ & $\begin{array}{c}0.001 \\
(0.001)\end{array}$ \\
\hline Finance sector & $\begin{array}{l}0.039 \\
(0.067)\end{array}$ & $\begin{array}{l}0.073)^{* *} \\
(0.031)^{*}\end{array}$ & $\begin{array}{l}0.0444^{* *} \\
(0.019)^{*}\end{array}$ & $\begin{array}{l}-0.1177^{* *} \\
(0.049)\end{array}$ & $\begin{array}{c}0.097 \\
(0.077)\end{array}$ & $\begin{array}{l}0.0788^{* *} \\
(0.032)^{*}\end{array}$ & $\begin{array}{l}0.050 \quad * * \\
(0.021)^{*}\end{array}$ & $\begin{array}{l}-0.128 * * \\
(0.053)\end{array}$ \\
\hline Risk aversion & $\begin{array}{l}-0.064 * * * \\
(0.015)\end{array}$ & & & & $\begin{array}{l}-0.190 * * * \\
(0.057)\end{array}$ & & & \\
\hline Demographics & yes & & yes & & yes & & yes & \\
\hline Income and wealth & yes & & yes & & yes & & yes & \\
\hline Macroarea & yes & & yes & & yes & & yes & \\
\hline \#obs & 1581 & & 1116 & & 1550 & & 1098 & \\
\hline Pseudo $R^{2}$ & 0.22 & & 0.13 & & 0.24 & & 0.14 & \\
\hline Instrumented endogenous regressors: & - & & - & & $\begin{array}{l}\text { Financial literacy } \\
\text { Trust in advisor }\end{array}$ & & - & \\
\hline Wu-Hausman test ( $(2(2) p$-value) & & & & & 0.00 & & 0.12 & \\
\hline $\begin{array}{l}\text { Test of instruments' validitv: } \\
\text { - F-test: }\end{array}$ & & & & & & & & \\
\hline $\begin{array}{l}\text { Financial literacy } \\
\text { p-value }\end{array}$ & & & & & $\begin{array}{l}7.84 \\
0.00\end{array}$ & & & \\
\hline Trust in advisor & & & & & 12.10 & & & \\
\hline p-value & & & & & 0.00 & & & \\
\hline
\end{tabular}

Notes: Demographics includes age, age squared, dummy for gender, years at school, dummy for self-employment, dummy for retirement status, number of years at Unicredit Bank. Income and wealth includes the (log of) individual income and the financial wealth brackets. Macroarea considers the North-West, the North-East, the Center and the South-Islands geographical areas. Source: UCS (2007) 


\section{Table 4: Monitoring and Financial Literacy}

This table reports the marginal effects on conditional probability of a probit model with double sample selection. Column (1) reports results of the 1st level selection equation Hold risky assets while column (2) reports results of the 2nd level selection equation of seeking for financial counselling (either Advice/Delegate). Risk aversion is the exclusion restriction of the 1st level selection equation while Expected payoff of advice/delegate is the exclusion restriction of the 2nd level selection equation. The columns (3a)-(5b) report results of the Monitoring outcome equation, estimated as a Heckman probit model with double sample selection. The columns (\#a) refer to the overall sample (advice/delegate) while the columns (\#b) refer to the subsample of those asking advice and deciding autonomously (advice only). The columns (3a)-(3b) consider as regressor the variable Financial Literacy, the columns (4a)-(4b) consider as regressor the highest percentiles of the variable Financial literacy (Financial Literacy_high), and the columns (5)-(5b) consider as regressors the highest and medium percentiles of the variable Financial Literacy (Financial Literacy_high and Financial Literacy_medium, respectively). The endogenous regressors Financial Literacy and Trust in advisor are instrumented by Regional Financial literacy, School performance, Generalized Trust_1 and Generalized Trust_2 (see Appendix A for details on the variables). Consistently with the results of the Wu-Hausman test reported, the Instrumental Variable regression is implemented in the 1st level selection equation. Tests of instruments' validity are reported at the bottom of the table. Heteroskedasticity robust standard errors are reported in parentheses. ***, **, and $*$ indicate significance at the 1, 5, and $10 \%$ levels, respectively.

\begin{tabular}{|c|c|c|c|c|c|c|c|c|}
\hline & \multirow{2}{*}{$\begin{array}{l}\text { 1st level selection } \\
\text { Hold risky assets }\end{array}$} & \multirow{2}{*}{$\frac{\text { 2nd level selection }}{\text { Advice/Delegate }}$} & \multicolumn{6}{|c|}{ outcome equation } \\
\hline & & & \multicolumn{6}{|c|}{ Monitoring } \\
\hline & (1) & (2) & (3a) & (3b) & (4a) & (4b) & (5a) & (5b) \\
\hline \multirow[t]{2}{*}{ Trust in advisor } & $0.323 \quad * * *$ & $0.148 * * *$ & -0.006 & -0.018 & 0.001 & -0.010 & -0.016 & -0.018 \\
\hline & $(0.064)$ & $(0.015)$ & $(0.049)$ & $(0.056)$ & $(0.049)$ & $(0.056)$ & $(0.048)$ & $(0.055)$ \\
\hline \multirow[t]{2}{*}{ Financial Literacy } & $0.223 \quad * * *$ & -0.019 & $0.018 *$ & $0.019 *$ & & & & \\
\hline & $(0.057)$ & $(0.012)$ & $(0.010)$ & $(0.011)$ & & & & \\
\hline \multirow[t]{2}{*}{ Financial Literacy_high } & & & & & $0.060^{* *}$ & $0.060 *$ & $0.110^{* * *}$ & $0.092 * *$ \\
\hline & & & & & $(0.030)$ & $(0.032)$ & $(0.040)$ & $(0.045)$ \\
\hline \multirow[t]{2}{*}{ Financial Literacy_medium } & & & & & & & $0.061 *$ & 0.039 \\
\hline & & & & & & & $(0.033)$ & $(0.040)$ \\
\hline \multirow[t]{2}{*}{ Self-assessed financial knowledge } & $-0.049 *$ & $0.040 *$ & $0.039 *$ & $0.074^{* * *}$ & $0.041^{* *}$ & $0.078^{* * *}$ & 0.033 & $0.073^{* * *}$ \\
\hline & $(0.026)$ & $(0.021)$ & $(0.021)$ & $(0.024)$ & $(0.020)$ & $(0.023)$ & $(0.021)$ & $(0.024)$ \\
\hline \multirow[t]{2}{*}{ Experience } & 0.002 & -0.001 & $0.002 *$ & 0.002 & $0.002 *$ & 0.002 & $0.002 *$ & 0.002 \\
\hline & $(0.002)$ & $(0.002)$ & $(0.001)$ & $(0.001)$ & $(0.001)$ & $(0.001)$ & $(0.001)$ & $(0.001)$ \\
\hline \multirow[t]{2}{*}{ Finance sector } & 0.102 & 0.043 & 0.029 & 0.048 & 0.032 & 0.055 & 0.021 & 0.047 \\
\hline & $(0.077)$ & $(0.072)$ & $(0.065)$ & $(0.072)$ & $(0.065)$ & $(0.072)$ & $(0.032)$ & $(0.037)$ \\
\hline \multirow[t]{2}{*}{ Expected payoff of advice/delegate } & -0.036 & $0.070 * *$ & & & & & & \\
\hline & $(0.024)$ & $(0.031)$ & & & & & & \\
\hline \multirow[t]{2}{*}{ Risk aversion } & $-0.060 \quad * * *$ & & & & & & & \\
\hline & $(0.015)$ & & & & & & & \\
\hline Demographics & yes & yes & yes & yes & yes & yes & yes & yes \\
\hline Income and wealth & yes & yes & yes & yes & yes & yes & yes & yes \\
\hline Macroarea & yes & yes & yes & yes & yes & yes & yes & yes \\
\hline \#obs & 1550 & 1098 & 704 & 510 & 704 & 510 & 704 & 510 \\
\hline Pseudo $\mathrm{R}^{2}$ & 0.24 & 0.12 & 0.09 & 0.13 & 0.10 & 0.13 & 0.10 & 0.13 \\
\hline \multirow{2}{*}{ Instrumented endogenous regressors: } & Financial literacy & - & \multirow{2}{*}{\multicolumn{6}{|c|}{-}} \\
\hline & Trust in advisor & & & & & & & \\
\hline Wu-Hausman test ( $\chi 2(2) \quad p$-value) & 0.00 & 0.39 & \multicolumn{6}{|c|}{0.52} \\
\hline \multicolumn{9}{|l|}{ Test of instruments' validity: } \\
\hline \multicolumn{9}{|l|}{ - F-test: } \\
\hline Financial literacy & 7.75 & & & & & & & \\
\hline p-value & 0.00 & & & & & & & \\
\hline Trust in advisor & 11.33 & & & & & & & \\
\hline $\mathrm{p}$-value & 0.00 & & & & & & & \\
\hline - Hansen-J statistic : & 0.71 & & & & & & & \\
\hline$\chi 2(2) p$-value & 0.70 & & & & & & & \\
\hline
\end{tabular}

Notes: Demographics includes age, age squared, dummy for gender, years at school, dummy for self-employment, dummy for retirement status, number of years at Unicredit Bank. Income and wealth includes the (log of) individual income and the financial wealth brackets. Macroarea considers the North-West, the North-East, the Center and the South-Islands geographical areas. Source: UCS (2007). 


\section{Table 5: Second opinion and Financial Literacy}

This table reports the marginal effects on conditional probability of a probit model with double sample selection. Column (1) reports results of the 1st level selection equation Hold risky assets while column (2) reports results of the 2nd level selection equation of seeking for financial counselling (either Advice/Delegate). Risk aversion is the exclusion restriction of the 1st level selection equation while Expected payoff of advice/delegate is the exclusion restriction of the 2nd level selection equation. The columns (3a)-(5b) report results of the Second opinion outcome equation, estimated as a Heckman probit model with double sample selection. The columns (\#a) refer to the overall sample (advice/delegate) while the columns (\#b) refer to the subsample of those asking advice and deciding autonomously (advice only). The columns (3a)-(3b) consider as regressor the variable Financial Literacy, the columns (4a)-(4b) consider as regressor the lowest percentiles of the variable Financial literacy (Financial Literacy_low), and the columns (5)-(5b) consider as regressors the lowest and medium percentiles of the variable Financial Literacy (Financial Literacy_low and Financial Literacy_medium, respectively). The endogenous regressors Financial Literacy and Trust in advisor are instrumented by Regional Financial literacy, School performance, Generalized Trust_1 and Generalized Trust_2 (see Appendix A for details on the variables). Consistently with the results of the Wu-Hausman test reported, the Instrumental Variable regression is implemented in the 1st level selection equation. Tests of instruments' validity are reported at the bottom of the table. Heteroskedasticity robust standard errors are reported in parentheses. ***, **, and $*$ indicate significance at the 1,5 , and $10 \%$ levels, respectively.

\begin{tabular}{|c|c|c|c|c|c|c|c|c|}
\hline & \multirow{2}{*}{$\begin{array}{l}\text { 1st level selection } \\
\text { Hold risky assets }\end{array}$} & \multirow{3}{*}{$\begin{array}{c}\frac{\text { 2nd level selection }}{\text { Advice/Delegate }} \\
\text { (2) }\end{array}$} & \multicolumn{6}{|c|}{ outcome equation } \\
\hline & & & \multicolumn{6}{|c|}{ Second opinion } \\
\hline & (1) & & (3a) & (3b) & (4a) & (4b) & (5a) & (5b) \\
\hline \multirow[t]{2}{*}{ Trust in advisor } & $0.323 * * *$ & $0.148 * * *$ & -0.030 & 0.007 & -0.024 & 0.005 & -0.036 & -0.001 \\
\hline & $(0.064)$ & $(0.015)$ & $(0.039)$ & $(0.048)$ & $(0.037)$ & $(0.047)$ & $(0.038)$ & $(0.048)$ \\
\hline \multirow[t]{2}{*}{ Financial Literacy } & $0.223 \quad * * *$ & -0.019 & 0.000 & -0.015 & & & & \\
\hline & $(0.057)$ & $(0.012)$ & $(0.009)$ & $(0.011)$ & & & & \\
\hline \multirow[t]{2}{*}{ Financial Literacy_low } & & & & & 0.028 & $0.085 * *$ & 0.008 & $0.072 *$ \\
\hline & & & & & $(0.032)$ & $(0.039)$ & $(0.036)$ & $(0.043)$ \\
\hline \multirow[t]{2}{*}{ Financial Literacy_medium } & & & & & & & -0.029 & -0.019 \\
\hline & & & & & & & $(0.024)$ & $(0.027)$ \\
\hline \multirow[t]{2}{*}{ Self-assessed financial knowledge } & $-0.049 *$ & $0.040 *$ & $0.065 * * *$ & $0.079^{* * *}$ & $0.069 * * *$ & $0.083^{* * *}$ & $0.065^{* * *}$ & $0.080 * * *$ \\
\hline & $(0.026)$ & $(0.021)$ & $(0.019)$ & $(0.023)$ & $(0.019)$ & $(0.023)$ & $(0.019)$ & $(0.023)$ \\
\hline \multirow[t]{2}{*}{ Experience } & 0.002 & -0.001 & 0.001 & 0.002 & 0.001 & 0.002 & 0.001 & 0.002 \\
\hline & $(0.002)$ & $(0.002)$ & $(0.001)$ & $(0.001)$ & $(0.001)$ & $(0.001)$ & $(0.001)$ & $(0.001)$ \\
\hline \multirow[t]{2}{*}{ Finance sector } & 0.102 & 0.043 & 0.014 & -0.021 & 0.018 & -0.022 & 0.012 & -0.025 \\
\hline & $(0.077)$ & $(0.072)$ & $(0.058)$ & $(0.073)$ & $(0.058)$ & $(0.073)$ & $(0.025)$ & $(0.031)$ \\
\hline \multirow[t]{2}{*}{ Expected payoff of advice/delegate } & -0.036 & $0.070 * *$ & & & & & & \\
\hline & $(0.024)$ & $(0.031)$ & & & & & & \\
\hline \multirow[t]{2}{*}{ Risk aversion } & $-0.060 \quad * * *$ & & & & & & & \\
\hline & $(0.015)$ & & & & & & & \\
\hline Demographics & yes & yes & yes & yes & yes & yes & yes & yes \\
\hline Income and wealth & yes & yes & yes & yes & yes & yes & yes & yes \\
\hline Macroarea & yes & yes & yes & yes & yes & yes & yes & yes \\
\hline \#obs & 1550 & 1098 & 704 & 510 & 704 & 510 & 704 & 510 \\
\hline Pseudo $R^{2}$ & 0.24 & 0.12 & 0.17 & 0.18 & 0.17 & 0.19 & 0.18 & 0.19 \\
\hline \multirow{2}{*}{ Instrumented endogenous regressors: } & Financial literacy & - & \multirow{2}{*}{\multicolumn{6}{|c|}{-}} \\
\hline & Trust in advisor & & & & & & & \\
\hline Wu-Hausman test ( $(\chi 2(2) p$-value) & 0.00 & 0.39 & \multicolumn{6}{|c|}{0.12} \\
\hline \multicolumn{9}{|l|}{ Test of instruments ' validity: } \\
\hline \multicolumn{9}{|l|}{ - F-test: } \\
\hline Financial literacy & 7.75 & & & & & & & \\
\hline $\mathrm{p}$-value & 0.00 & & & & & & & \\
\hline Trust in advisor & 11.33 & & & & & & & \\
\hline p-value & 0.00 & & & & & & & \\
\hline - Hansen-J statistic : & 0.71 & & & & & & & \\
\hline$\chi 2$ (2) $p$-value & 0.70 & & & & & & & \\
\hline
\end{tabular}

Notes: Demographics includes age, age squared, dummy for gender, years at school, dummy for self-employment, dummy for retirement status, number of years at Unicredit Bank. Income and wealth includes the (log of) individual income and the financial wealth brackets. Macroarea considers the North-West, the North-East, the Center and the South-Islands geographical areas. Source: UCS (2007). 


\section{Robustness section}

Table 3a. Demand for advice and Trust in advisor_ 1

This table reports robustness checks of the main findings reported in Table 3. The variable Trust in advisor is replaced here by its binary version, Trust in advisor_ 1. The results of the Wu-Hausman tests suggests to instrument endogenous regressors in both selection and outcome equations. Dependent variable and regression techniques are the same as Table 3. Heteroskedasticity robust standard errors are reported in parentheses. ${ }^{* *},{ }^{* *}$, and ${ }^{*}$ indicate significance at the 1,5 , and $10 \%$ levels, respectively.

\begin{tabular}{|c|c|c|c|c|}
\hline & $\frac{\text { Selection }}{\text { Hold risky assets }}$ & Self & Advice & Delegation \\
\hline & (1) & (2a) & (2b) & (2c) \\
\hline \multirow[t]{2}{*}{ Trust in advisor_1 } & $0.087 \quad * * *$ & $-0.438 * * *$ & $-0.257^{* * *}$ & $0.695 * * *$ \\
\hline & $(0.022)$ & $(0.138)$ & $(0.087)$ & $(0.216)$ \\
\hline \multirow[t]{2}{*}{ Financial Literacy } & $0.036 \quad * * *$ & 0.023 & 0.014 & -0.037 \\
\hline & $(0.007)$ & $(0.036)$ & $(0.022)$ & $(0.058)$ \\
\hline \multirow[t]{2}{*}{ Self-assessed financial knowledge } & 0.006 & 0.016 & 0.009 & -0.025 \\
\hline & $(0.018)$ & $(0.016)$ & $(0.010)$ & $(0.026)$ \\
\hline \multirow[t]{2}{*}{ Experience } & $0.005 \quad * * *$ & -0.001 & -0.001 & 0.002 \\
\hline & $(0.001)$ & $(0.001)$ & $(0.001)$ & $(0.002)$ \\
\hline \multirow[t]{2}{*}{ Finance sector } & $0.170^{* *}$ & $0.072 *$ & $0.042 *$ & $-0.115 *$ \\
\hline & $(0.082)$ & $(0.037)$ & $(0.022)$ & $(0.059)$ \\
\hline \multirow[t]{2}{*}{ Risk aversion } & $-0.061 \quad * * *$ & & & \\
\hline & $(0.015)$ & & & \\
\hline Demographics & yes & & yes & \\
\hline Income and wealth & yes & & yes & \\
\hline Macroarea & yes & & yes & \\
\hline \#obs & 1550 & & 1098 & \\
\hline Pseudo $\mathrm{R}^{2}$ & 0.25 & & 0.10 & \\
\hline \multirow[t]{2}{*}{ Instrumented endogenous regressors: } & Financial literacy & & Financial literacy & \\
\hline & Trust in advisor & & Trust in advisor & \\
\hline Wu-Hausman test ( $(2$ (2) p-value) & 0.00 & & 0.06 & \\
\hline \multicolumn{5}{|l|}{ Test of instruments' validity: } \\
\hline \multicolumn{5}{|l|}{ - F-test : } \\
\hline Financial literacy & 7.84 & & 20.18 & \\
\hline p-value & 0.00 & & 0.00 & \\
\hline Trust in advisor & 8.56 & & 16.27 & \\
\hline p-value & 0.00 & & 0.00 & \\
\hline - Hansen-J statistic : & 0.23 & & 1.27 & \\
\hline$x 2(2) p$-value & 0.89 & & 0.53 & \\
\hline
\end{tabular}

Notes: Demographics includes age, age squared, dummy for gender, years at school, dummy for self-employment, dummy for retirement status, number of years at Unicredit Bank. Income and wealth includes the (log of) individual income and the financial wealth brackets. Macroarea considers the North-West, the North-East, the Center and the South-Islands geographical areas. Source: UCS (2007). 


\section{Table 4a. Monitoring and investor Financial Literacy_ 1}

This table reports robustness checks of the main findings reported in Table 4. The variable Financial Literacy is replaced by Financial Literacy_ 1 (see Appendix A for details on the construction of the variable). Dependent variable and regression techniques are the same as Table 4 . Heteroskedasticity robust standard errors are reported in parentheses. ***, **, and * indicate significance at the 1,5 , and $10 \%$ levels, respectively.

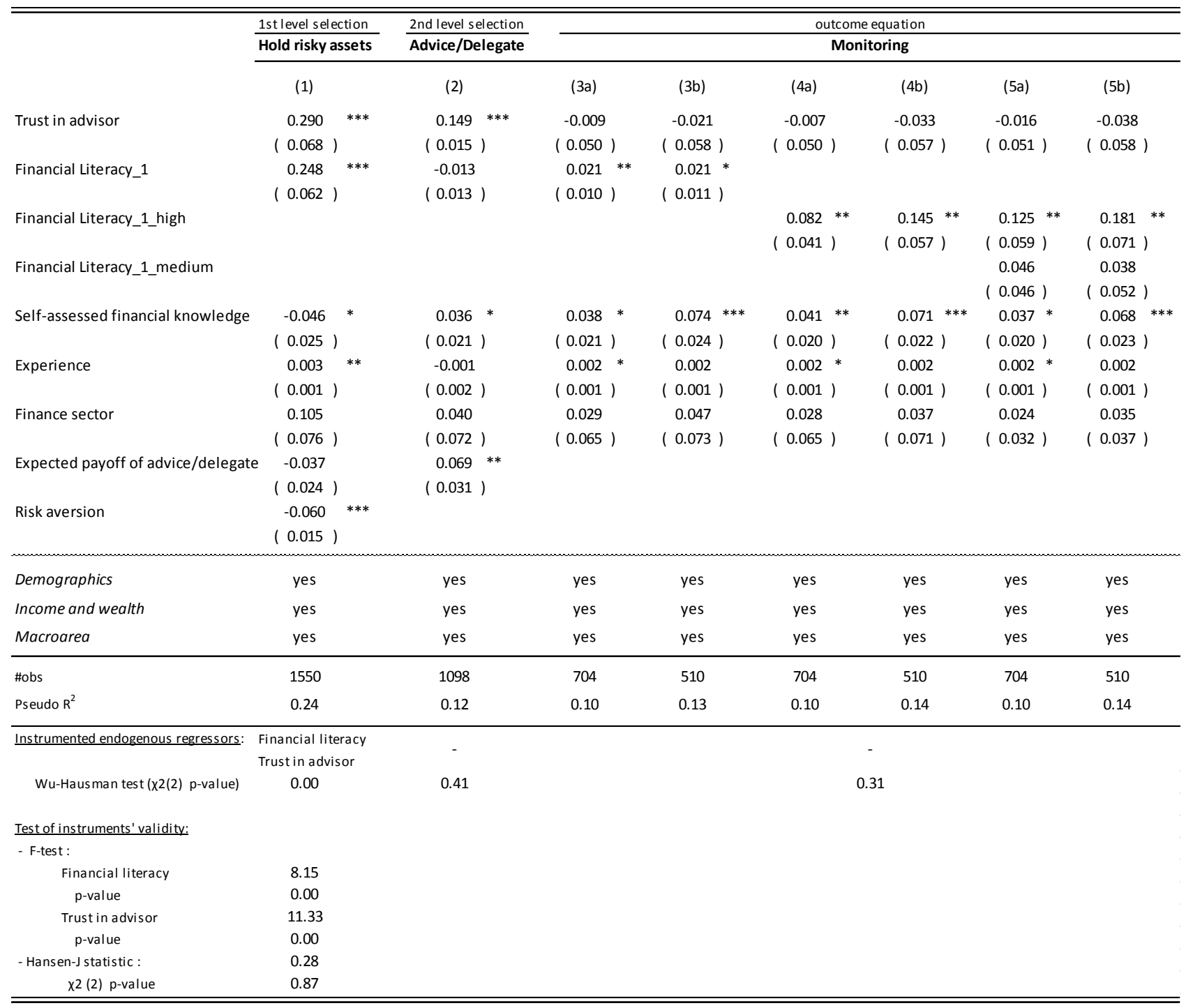

Notes: Demographics includes age, age squared, dummy for gender, years at school, dummy for self-employment, dummy for retirement status, number of years at Unicredit Bank. Income and wealth includes the (log of) individual income and the financial wealth brackets. Macroarea considers the North-West, the North-East, the Center and the South-Islands geographical areas. Source: UCS (2007). 


\section{Table 4b. Monitoring and investor Financial Literacy_2}

This table reports robustness checks of the main findings reported in Table 4. The variable Financial Literacy is replaced by Financial Literacy_2 (see Appendix A for details on the construction of the variable). Dependent variable and regression techniques are the same as Table 4 . Heteroskedasticity robust standard errors are reported in parentheses. ***, **, and * indicate significance at the 1,5 , and $10 \%$ levels, respectively.

\begin{tabular}{|c|c|c|c|c|c|c|c|c|c|}
\hline & \multirow{2}{*}{\multicolumn{2}{|c|}{$\begin{array}{l}\text { 1st level selection } \\
\text { Hold risky assets }\end{array}$}} & \multirow{3}{*}{$\begin{array}{c}\frac{2 \text { nd level selection }}{\text { Advice/Delegate }} \\
\text { (2) }\end{array}$} & \multicolumn{6}{|c|}{ outcome equation } \\
\hline & & & & \multicolumn{6}{|c|}{ Monitoring } \\
\hline & (1) & & & (3a) & (3b) & (4a) & (4b) & (5a) & (5b) \\
\hline \multirow[t]{2}{*}{ Trust in advisor } & $0.268 * *$ & $k * *$ & $0.451 * * *$ & -0.014 & -0.022 & -0.023 & -0.041 & -0.036 & -0.045 \\
\hline & $(0.074)$ & & $(0.052)$ & $(0.048)$ & $(0.055)$ & $(0.047)$ & $(0.054)$ & $(0.046)$ & $(0.054)$ \\
\hline \multirow[t]{2}{*}{ Financial Literacy_2 } & $0.292 \quad * *$ & *** & $-0.075 *$ & $0.019 *$ & 0.018 & & & & \\
\hline & $(0.082)$ & & $(0.039)$ & $(0.010)$ & ( 0.011$)$ & & & & \\
\hline \multirow[t]{2}{*}{ Financial Literacy_2_high } & & & & & & $0.098 * * *$ & $0.119 * * *$ & $0.135^{* * *}$ & $0.133 * * *$ \\
\hline & & & & & & $(0.034)$ & $(0.040)$ & $(0.043)$ & $(0.050)$ \\
\hline \multirow[t]{2}{*}{ Financial Literacy_2_medium } & & & & & & & & 0.042 & 0.016 \\
\hline & & & & & & & & $(0.032)$ & $(0.038)$ \\
\hline \multirow[t]{2}{*}{ Self-assessed financial knowledge } & $-0.078 * *$ & ** & $0.119 *$ & $0.037 *$ & $0.074 * * *$ & 0.031 & $0.064 * * *$ & 0.025 & $0.062 * * *$ \\
\hline & $(0.036)$ & & $(0.064)$ & $(0.021)$ & $(0.024)$ & $(0.019)$ & $(0.022)$ & $(0.020)$ & $(0.023)$ \\
\hline \multirow[t]{2}{*}{ Experience } & 0.002 & & -0.002 & $0.002 *$ & 0.002 & $0.002 *$ & 0.002 & $0.002 *$ & 0.002 \\
\hline & $(0.002)$ & & $(0.005)$ & $(0.001)$ & $(0.001)$ & $(0.001)$ & $(0.001)$ & $(0.001)$ & $(0.001)$ \\
\hline \multirow[t]{2}{*}{ Finance sector } & 0.109 & & 0.136 & 0.027 & 0.046 & 0.018 & 0.039 & 0.009 & 0.035 \\
\hline & $(0.078)$ & & $(0.221)$ & $(0.065)$ & $(0.072)$ & $(0.065)$ & $(0.072)$ & $(0.032)$ & $(0.037)$ \\
\hline \multirow[t]{2}{*}{ Expected payoff of advice/delegate } & $-0.046 *$ & & $0.212 * *$ & & & & & & \\
\hline & $(0.024)$ & & $(0.096)$ & & & & & & \\
\hline \multirow[t]{2}{*}{ Risk aversion } & $-0.060 * *$ & & & & & & & & \\
\hline & $(0.015)$ & & & & & & & & \\
\hline Demographics & yes & & yes & yes & yes & yes & yes & yes & yes \\
\hline Income and wealth & yes & & yes & yes & yes & yes & yes & yes & yes \\
\hline Macroarea & yes & & yes & yes & yes & yes & yes & yes & yes \\
\hline \#obs & 1550 & & 1098 & 704 & 510 & 704 & 510 & 704 & 510 \\
\hline Pseudo $\mathrm{R}^{2}$ & 0.24 & & 0.12 & 0.09 & 0.12 & 0.10 & 0.14 & 0.11 & 0.14 \\
\hline \multirow[t]{2}{*}{ Instrumented endogenous regressors: } & Financial literac & & - & \multirow{2}{*}{\multicolumn{6}{|c|}{ - }} \\
\hline & Trust in advisor & & - & & & & & & \\
\hline Wu-Hausman test (x2(2) p-value) & 0.00 & & 0.41 & \multicolumn{6}{|c|}{0.31} \\
\hline \multicolumn{10}{|l|}{ Test of instruments' validity: } \\
\hline \multicolumn{10}{|l|}{$\overline{-F \text {-test: }}$} \\
\hline Financial literacy & 6.76 & & & & & & & & \\
\hline p-value & 0.00 & & & & & & & & \\
\hline Trust in advisor & 11.33 & & & & & & & & \\
\hline $\mathrm{p}$-value & 0.00 & & & & & & & & \\
\hline - Hansen-J statistic : & 0.50 & & & & & & & & \\
\hline$\chi 2(2) p$-value & 0.78 & & & & & & & & \\
\hline
\end{tabular}

Notes: Demographics includes age, age squared, dummy for gender, years at school, dummy for self-employment, dummy for retirement status, number of years at Unicredit Bank. Income and wealth includes the (log of) individual income and the financial wealth brackets. Macroarea considers the North-West, the North-East, the Center and the South-Islands geographical areas. Source: UCS (2007). 


\section{Table 5a. Second opinion and investor Financial Literacy_ 1}

This table reports robustness checks of the main findings reported in Table 5. The variable Financial Literacy is replaced by Financial Literacy_ 1 (see Appendix A for details on the construction of the variable). Dependent variable and regression techniques are the same as Table 5. Heteroskedasticity robust standard errors are reported in parentheses. ***, **, and * indicate significance at the 1,5 , and $10 \%$ levels, respectively.

\begin{tabular}{|c|c|c|c|c|c|c|c|c|c|}
\hline & \multirow{2}{*}{\multicolumn{2}{|c|}{$\frac{1 \text { st level selection }}{\text { Hold risky assets }}$}} & \multirow{2}{*}{$\frac{2 \text { nd level selection }}{\text { Advice/Delegate }}$} & \multicolumn{6}{|c|}{ outcome equation } \\
\hline & & & & \multicolumn{6}{|c|}{ Second opinion } \\
\hline & (1) & & $(2)$ & (3a) & $(3 b)$ & (4a) & (4b) & (5a) & $(5 b)$ \\
\hline \multirow[t]{2}{*}{ Trust in advisor } & $0.290 *$ & $* * *$ & $0.149 * * *$ & -0.036 & -0.002 & -0.034 & 0.000 & -0.028 & 0.011 \\
\hline & $(0.068)$ & & $(0.015)$ & $(0.040)$ & $(0.049)$ & ( 0.039$)$ & $(0.050)$ & $(0.040)$ & $(0.049)$ \\
\hline \multirow[t]{2}{*}{ Financial Literacy_1 } & $0.248 *$ & $* * *$ & -0.013 & -0.001 & $-0.020 *$ & & & & \\
\hline & $(0.062)$ & & $(0.013)$ & $(0.009)$ & $(0.011)$ & & & & \\
\hline \multirow[t]{2}{*}{ Financial Literacy_1_low } & & & & & & 0.021 & $0.089 *$ & 0.048 & $0.153 * *$ \\
\hline & & & & & & $(0.043)$ & $(0.052)$ & $(0.050)$ & $(0.059)$ \\
\hline \multirow[t]{2}{*}{ Financial Literacy_1_medium } & & & & & & & & 0.030 & $0.072 *$ \\
\hline & & & & & & & & $(0.029)$ & $(0.038)$ \\
\hline \multirow[t]{2}{*}{ Self-assessed financial knowledge } & $-0.046 *$ & & $0.036 *$ & $0.064 * * *$ & $0.077 * * *$ & $0.065 * * *$ & $0.075 * * *$ & $0.067^{* * *}$ & $0.080 * * *$ \\
\hline & $(0.025)$ & & ( 0.021$)$ & $(0.019)$ & $(0.022)$ & $(0.018)$ & $(0.023)$ & $(0.019)$ & $(0.022)$ \\
\hline \multirow[t]{2}{*}{ Experience } & $0.003 *$ & $* *$ & -0.001 & 0.001 & 0.002 & 0.001 & 0.002 & 0.001 & 0.002 \\
\hline & ( 0.001$)$ & & $(0.002)$ & $(0.001)$ & $(0.001)$ & $(0.001)$ & $(0.001)$ & $(0.001)$ & $(0.001)$ \\
\hline \multirow[t]{2}{*}{ Finance sector } & 0.105 & & 0.040 & 0.012 & -0.025 & 0.013 & -0.026 & 0.015 & -0.020 \\
\hline & $(0.076)$ & & $(0.072)$ & $(0.058)$ & $(0.073)$ & $(0.058)$ & $(0.072)$ & $(0.025)$ & $(0.030)$ \\
\hline \multirow[t]{2}{*}{ Expected payoff of advice/delegate } & -0.037 & & $0.069 * *$ & & & & & & \\
\hline & $(0.024)$ & & $(0.031)$ & & & & & & \\
\hline \multirow[t]{2}{*}{ Risk aversion } & $-0.060 *$ & $* * *$ & & & & & & & \\
\hline & $(0.015)$ & & & & & & & & \\
\hline Demographics & yes & & yes & yes & yes & yes & yes & yes & yes \\
\hline Income and wealth & yes & & yes & yes & yes & yes & yes & yes & yes \\
\hline Macroarea & yes & & yes & yes & yes & yes & yes & yes & yes \\
\hline \#obs & 1550 & & 1098 & 704 & 510 & 704 & 510 & 704 & 510 \\
\hline Pseudo $\mathrm{R}^{2}$ & 0.24 & & 0.12 & 0.17 & 0.19 & 0.17 & 0.18 & 0.18 & 0.19 \\
\hline \multirow[t]{2}{*}{ Instrumented endogenous regressors: } & Financial literac & & - & \multirow{2}{*}{\multicolumn{6}{|c|}{-}} \\
\hline & Trust in advisor & & - & & & & & & \\
\hline Wu-Hausman test ( $\chi 2(2) p$-value) & 0.00 & & 0.42 & \multicolumn{6}{|c|}{0.14} \\
\hline \multicolumn{10}{|l|}{ Test of instruments' validity: } \\
\hline \multicolumn{10}{|l|}{ - F-test: } \\
\hline Financial literacy & 8.15 & & & & & & & & \\
\hline $\mathrm{p}$-value & 0.00 & & & & & & & & \\
\hline Trust in advisor & 11.33 & & & & & & & & \\
\hline p-value & 0.00 & & & & & & & & \\
\hline - Hansen-J statistic : & 0.28 & & & & & & & & \\
\hline$\chi 2(2) p$-value & 0.87 & & & & & & & & \\
\hline
\end{tabular}

Notes: Demographics includes age, age squared, dummy for gender, years at school, dummy for self-employment, dummy for retirement status, number of years at Unicredit Bank. Income and wealth includes the (log of) individual income and the financial wealth brackets. Macroarea considers the North-West, the North-East, the Center and the South-Islands geographical areas. Source: UCS (2007). 


\section{Table 5b. Second opinion and investor Financial Literacy_2}

This table reports robustness checks of the main findings reported in Table 5. The variable Financial Literacy is replaced by Financial Literacy_2 (see Appendix A for details on the construction of the variable). Dependent variable and regression techniques are the same as Table 5. Consistently with the results of the Wu-Hausman test reported, the Instrumental Variable regression is implemented both in the 1st level selection and in the Second opinion outcome equation. Heteroskedasticity robust standard errors are reported in parentheses. ${ }^{* * *},{ }^{* *}$, and $*$ indicate significance at the 1,5 , and $10 \%$ levels, respectively.

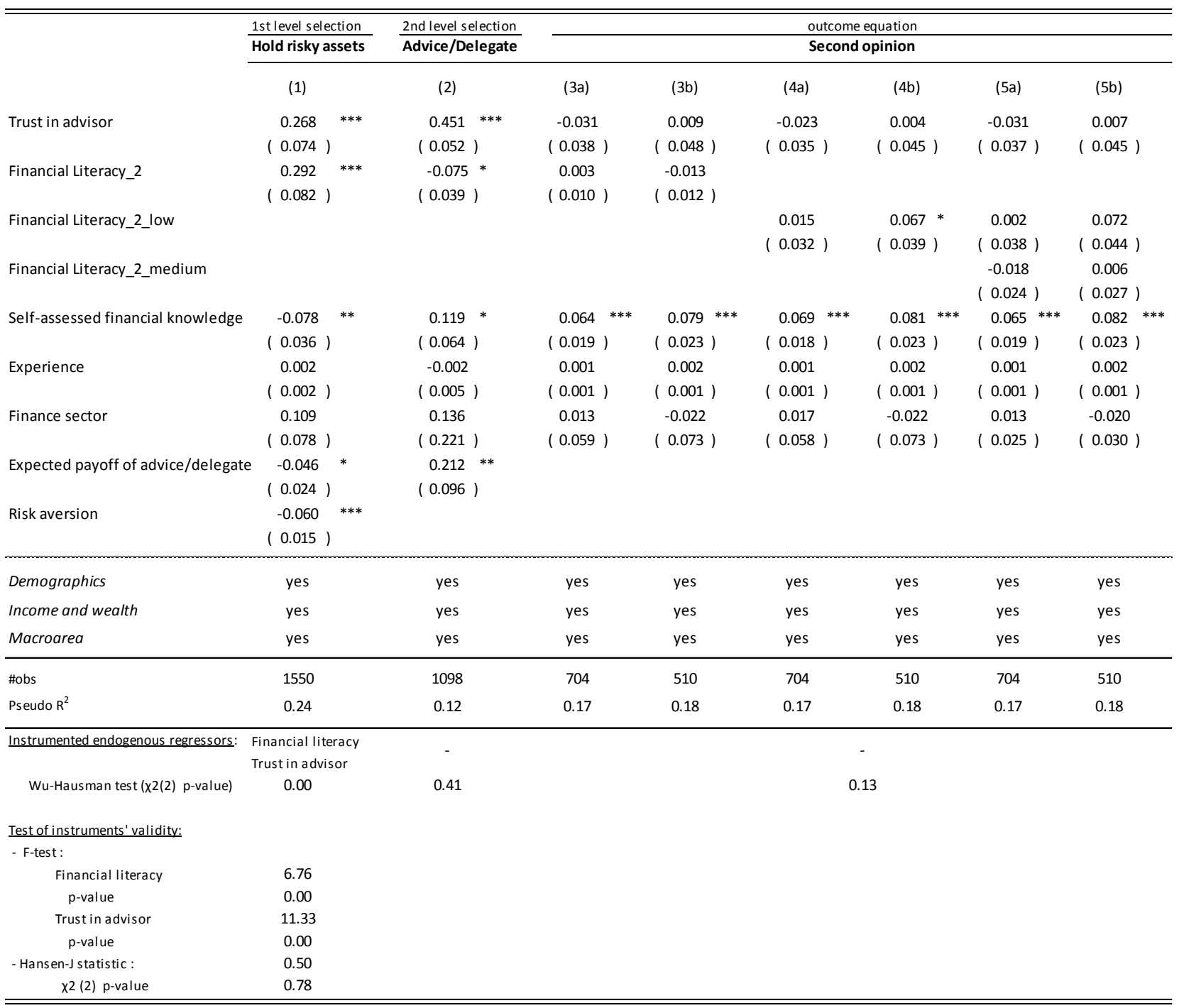

Notes: Demographics includes age, age squared, dummy for gender, years at school, dummy for self-employment, dummy for retirement status, number of years at Unicredit Bank. Income and wealth includes the (log of) individual income and the financial wealth brackets. Macroarea considers the North-West, the North-East, the Center and the South-Islands geographical areas. Source: UCS (2007). 


\section{Figures}

\section{Figure 1. Financial literacy distribution}

This figure represents the distribution of the variable Financial Literacy which captures the number of correct answers to eight questions (see Appendix A for details on the construction of the variable).

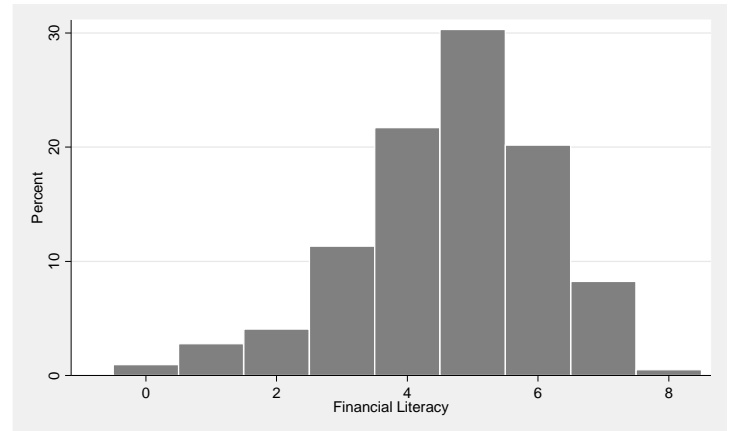

Source: UCS (2007)

\section{Figure 1a. Financial literacy_ 1 distribution}

This figure represents the distribution of the variable Financial Literacy_ 1 which captures the number of correct answers to seven questions (see Appendix A for details on the construction of the variable).

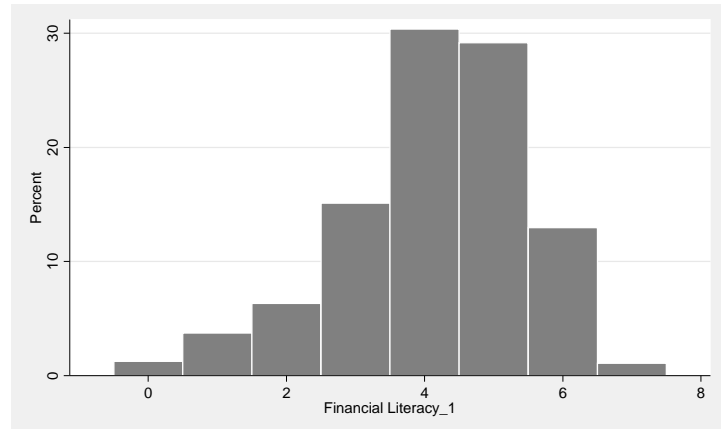

\section{Figure 1b. Financial literacy_2 distribution}

This figure represents the distribution of the variable Financial Literacy_2 which captures the number of correct answers to seven questions (see Appendix A for details on the construction of the variable).

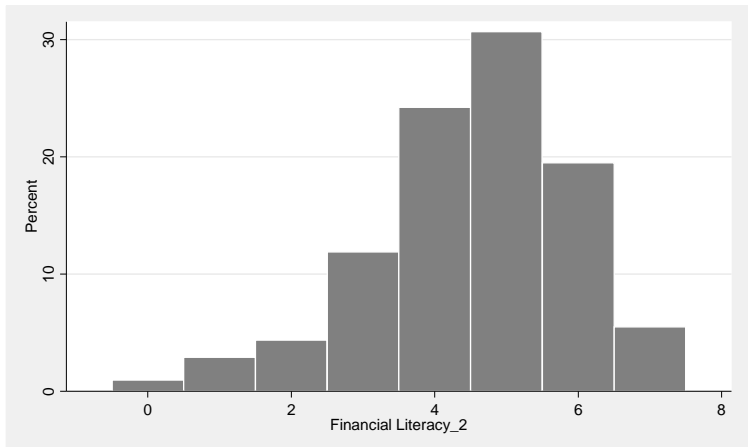




\section{Figure 2. Financial literacy cumulative distribution}

This figure represents the cumulative distribution function of the variable Financial Literacy which captures the number of correct answers to eight questions (see Appendix A for details on the construction of the variable).

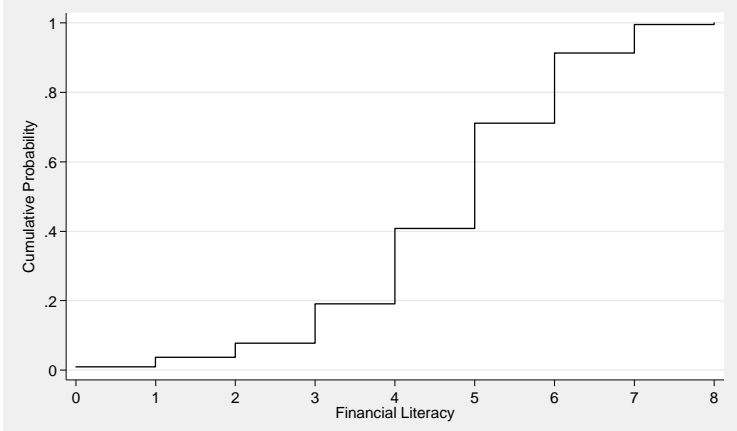

Source: UCS (2007)

\section{Figure 2a. Financial literacy_ 1 cumulative distribution}

This figure represents the cumulative distribution function of the variable Financial Literacy_ 1 which captures the number of correct answers to seven questions (see Appendix A for details on the construction of the variable).

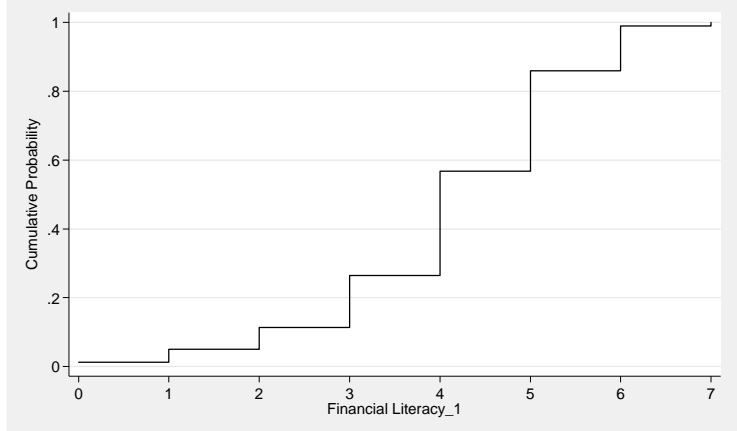

Source: UCS (2007)

\section{Figure 2b. Financial literacy_2 cumulative distribution}

This figure represents the cumulative distribution function of the variable Financial Literacy_2 which captures the number of correct answers to seven questions (see Appendix A for details on the construction of the variable).

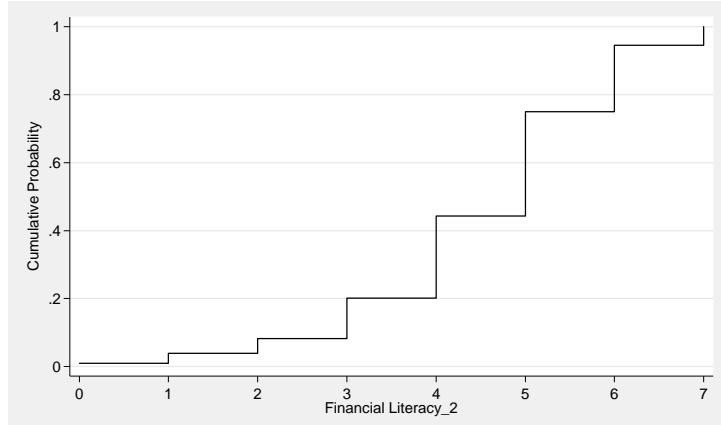

Source: UCS (2007) 


\section{Appendix A}

\section{Unicredit Investors Survey: description of the main variables}

The 2007 Unicredit Investors Survey (UCS), which draws from the population of clients of one of the three largest European banking groups, with over 4 million accounts in Italy. The 2007 wave interviewed 1,676 individuals with a current account in one of the banks that are part of the Unicredit Group based in Italy. The sample is representative of the eligible population of customers, excluding younger than 20 or older than 75, and those who hold accounts of less than 10,000 euro or more than 2.5 million euro.

The sample selection is based on individual clients of Unicredit, however the survey contains detailed information also on the head of household - defined as the person responsible for the financial matters of the family - and spouse, if present. As for the financial variables, they are elicited both at the respondent and household level. ${ }^{19}$

We restrict the sample to those investors for whom Unicredit is the main or only bank (1581 out of 1686)

Below we provide details for all relevant variables in the empirical analysis and report the survey variable label in brackets.

\section{Dependent variables}

\section{Holding risky assets (label: INVEST)}

This binary variable is based on the answer to the following question:

"Do you currently own, or have owned in the past, financial products other than current account (e.g, stocks, government bonds, mutual funds, etc.)?" The possible answers are YES/ YES, in the past/NO.

This variable takes value 1 if the answer is YES, 0 otherwise.

\section{Self-Advice-Delegation (label: MODINV)}

This variable separates, within the consulting activity, the role of advice and that of delegation. The measure adopted is based on the question "In managing your financial investment, which of these statements better describes your attitude? A: I prefer to decide autonomously: the bank just executes my dispositions; B: I discuss with my bank/advisor my intentions and ask an advice before taking a decision; C: I evaluate my bank's/advisor's proposals before taking a decision; D: I mainly rely on my bank/advisor for my investment decisions; E: I allow my bank (advisor) decide everything".

We construct a variable: "Self" if the answer is A, "Advice" if the answers are B-C and "Delegation" if the answers are D-E.

\section{Advice/Delegate (label: ADVICE)}

This binary variable is based on the answer (YES/NO) to following question: "Considering all banks/financial institutions you and your family have relationship with, do you rely on the advice of a financial consultant to make your investment choices?"

\section{Second opinion (label: MARCHE)}

It is a binary variable based on the answer (YES/NO) to following question:

"Have you ever asked your advisor products sold by other banks or financial intermediaries"

\footnotetext{
${ }^{19}$ Notice that the Unicredit sample is older, more educated, more likely to live in the North and with higher family income than the SHIW sample.
} 


\section{Monitoring (label: ADVFREQ)}

This measure is based on the following question "How often do you use your financial advisor as a source of financial information/ financial advice?"

The 10 possible answers range from "never" to "every day". We re-coded the variable in a binary version equal to 1 if the answers range from 4 to 10 , and 0 otherwise.

\section{Main regressors}

\section{Trust in advisor (label: ADVTRUST)}

The respondent is asked to answer the following question: "Overall, how much do you trust your bank or financial advisor concerning your investments?". The answer ranges from 1 (=no trust) to 5 (=trust a lot).

Trust in advisor_binary It is the binary version of the variable Trust in advisor. It is equal to 1 if Trust in advisor is larger than (or equal to) the median (3) and 0 otherwise

\section{Financial Literacy}

The respondent is awarded one point for answering correctly questions 1 to 8 . The variable therefore ranges from 0 to 8 .

1. Inflation (label: INFLATION)

Suppose a bank account yields a $2 \%$ interest per annum (after expenses and taxes). If actual inflation is $2 \%$ per year (assuming you did not access your account) after two years, the amount deposited can buy you (select one answer):

a) More than it can buy today; b) less than it can buy today; c) the same as it can buy today (correct); and d) cannot answer/cannot understand.

2. Interest rates (label: INTEREST)

Imagine having a 'tip' and knowing for certain that in six months interest rates will rise. Do you think it is appropriate to purchase fixed rate bonds today?

a) Yes; b) no (correct); c) I do not know.

3. Diversification 1 (label: DIVERSIF1)

In relation to investments, people often talk about diversification. In your opinion, to have proper diversification of one's investments means (select one response):

a) To have in one's investment portfolio bonds and shares; b) not to invest for too long in the same financial product; c) to invest in the greatest possible number of financial products; d) to invest simultaneously in multiple financial products to limit exposure to the risks associated with individual products (correct); e) to not invest in high-risk instruments; f) I do not know/cannot understand.

4. Diversification 2 (label: DIVERSIF2)

Which of these portfolios is better diversified?

a) $70 \%$ T-bills, 15\% European equity fund, 15\% in 2-3 Italian stocks ; b) $70 \%$ T-bills, $30 \%$ European equity fund; c) $70 \%$ T-bills, 30\% in 2-3 Italian stocks; d) $70 \%$ T-bills, $30 \%$ in stocks of companies I know well; e) Do not know

Four other financial literacy indicators are based on the question: How risky do you think these products are?

The answers range from $1=$ Not risky at all, to $5=$ Very risky, and 'Do not know' is always an option. One point is given if the respondent can correctly state that:

5. Private bonds are at least as risky as deposits (label: RISK1) 
6. Stocks are at least as risky as government bonds (label: RISK2)

7. Stocks mutual funds are at least as risky as mutual funds (label: RISK3)

8. Housing is at least as risky as deposits (label: RISK4)

"Financial Literacy_low" is a binary version of the variable capturing a low level of financial knowledge. It is equal to 1 if the Financial Literacy variable is smaller than (or equal to) 3, and 0 otherwise.

"Financial Literacy_medium" is a binary version of the variable capturing a medium level of financial knowledge. It is equal to 1 if the Financial Literacy variable is equal to 4 or 5 , and 0 otherwise.

"Financial Literacy_high" is a binary version of the variable capturing a high level of financial knowledge. It is equal to 1 if the Financial Literacy variable is larger than (or equal to) 6, and 0 otherwise.

\section{Financial Literacy_1}

The variable Financial Literacy_ 1 is similar to Financial Literacy with the exception of the exclusion of question 2 , being the one with the highest score of correct answers in the block of the first four questions. ${ }^{20}$ The variable therefore ranges from 0 to 7 .

"Financial Literacy_1_low" is a binary version of the variable capturing a low level of financial knowledge. It is equal to 1 if the Financial Literacy_ 1 variable is smaller than (or equal to) 2, and 0 otherwise.

"Financial Literacy_1_medium" is a binary version of the variable capturing a medium level of financial knowledge. It is equal to 1 if the Financial_ 1 Literacy variable is equal to 3, 4 or 5, and 0 otherwise.

"Financial Literacy_1_high" is a binary version of the variable capturing a high level of financial knowledge. It is equal to 1 if the Financial Literacy_ 1 variable is larger than (or equal to) 6, and 0 otherwise.

\section{Financial Literacy_2}

The variable Financial Literacy_2 is similar to Financial Literacy with the exception of the exclusion of question 4 , being the one with the lowest score of correct answers. The variable therefore ranges from 0 to 7.

"Financial Literacy_2_low" is a binary version of the variable capturing a low level of financial knowledge. It is equal to 1 if the Financial Literacy_2 variable is smaller than (or equal to) 3, and 0 otherwise.

"Financial Literacy_2_medium" is a binary version of the variable capturing a medium level of financial knowledge. It is equal to 1 if the Financial_2 Literacy variable is equal to 4, and 0 otherwise.

"Financial Literacy_2_high" is a binary version of the variable capturing a high level of financial knowledge. It is equal to 1 if the Financial Literacy_2 variable is larger than (or equal to) 5 , and 0 otherwise.

\section{Self-assessed financial knowledge (label: ABILITY)}

The respondent is asked: "Which is the degree of knowledge relative to ten assets (government bonds, repurchase agreements, private bonds, mutual funds, derivatives, unit-linked or index-linked life insurance, ETFs, managed portfolios, and structured products)?". The answers range from 1 (=not at all) to 5 (=very well). The index used in the analysis (1-5) is the average of these ten measures.

\footnotetext{
${ }^{20}$ In the second block, which is a composite test on the knowledge of risk, all four financial literacy indicators display a larger response rate than question 2 but we chose not to modify the second block. Indeed, by eliminating one of them the overall test on the knowledge of riskiness would be undermined while by eliminating all of them the variability of the variable would have shrunk from 0-8 to 0-4, thus making meaningless the split of the population in percentiles.
} 


\section{Risk aversion (label: PROPRISK)}

The variable is based on the question "In managing your financial investment which of these attitudes do you usually have? When I invest I usually look for Very high returns, even with a high risk of losing part of my principal (LOW); High returns with a fair degree of principal safety and Fair returns with high safety for my principal (MEDIUM); Low returns without risk of losing my principal (HIGH)". We re-code this variable in three levels of risk aversion (HIGH, MEDIUM, LOW).

\section{Expected payoff of advice/delegate (label: MOTVBA)}

This binary variable captures the expected payoff of seeking advice and should determine the choice of asking advice/delegation versus self-directing own investment.

To build our measure of expected payoff of advice/delegate we refer to Pesendorfer and Wolinsky (2003). The expected payoff of advice or delegate in equilibrium is ${ }^{21}: x V-p-s=V-p-2 s / x$. $V$ represents the value of the optimal recommended product, $p$ is the price, $s$ is the direct cost of control and $x$ is the level of effort of the advisor. $2 s / x$ represents the expected cost of control: the higher are the direct control costs (i.e., the search costs or opportunity costs of time) and/or the lower is the effort of the advisor, the higher are the expected control costs. The expression on the left-hand side is the value for investors who stop and buy the recommended product while the expression on the right-hand side is the value for investors who search for a second opinion: the two values equate in equilibrium.

To construct a proxy of this measure of "expected payoff of advice/delegate" we rely on the following composite question:

"If you had to choose a bank for your investments, how important would be the following factors in your final choice?" A. proximity to home/office; B: ample choice of products and services; C. good performance of products; D. good relationship with bank employees; E. consultants' competence; F. prices' competitiveness; G. innovative products and services; H. quality and completeness of communications and information (current account reporting, etc.); I. telephone and internet services.

The five possible answers range from "Not at all" (1) to "Very important" (5).

We proxy $V$ with the factor B (the utility attached to the optimal investor-specific product is larger if the choice of products is wider), $p$ with factor $\mathrm{F}$ and the expected control costs with a combination of factors A and I (proxying the opportunity cost of time), and of factors $\mathrm{C}$ and $\mathrm{E}$ (proxying the effort of the advisor).

The measure adopted in the main specification is a binary variable identifying a high expected payoff of advice/delegate.

It is equal to 1 if $\{\underbrace{B>=4}_{V \text { high }}, \underbrace{F>=4}_{p \text { low }} \underbrace{\underbrace{A<=3 \& I<=3}_{\text {low search cost }} \text { or } \underbrace{C>=4 \& E>=4}_{\text {high effort }}}_{\text {low expected control cost }}\}, 0$ otherwise.

Expected payoff of seeking advice_1 This measure is a variant of the measure Expected payoff of advice/delegate computed above, to test the sensitivity of the findings to a variation in the choice of cut-off answers.

\footnotetext{
${ }^{21}$ Pesendorfer and Wolinsky (2003), equation (6), page 424. Note that the full search cost would be $(d+s)$, where $d$ is the direct cost of advice, but it can be discarded because Pesendorfer and Wolinsky (2003) show that it equals 0 in equilibrium (see Proposition 1 on pag. 426)
} 
It is equal to 1 if $\{\underbrace{B>4}_{V \text { high }}, \underbrace{F>4}_{p \text { low }}, \underbrace{A<3 \& I<3}_{\text {low expected control cost }}$ or $\underbrace{C>4 \& E>4}_{\text {high effort }}\}, 0$ otherwise.

Expected payoff of seeking advice_2 This measure is a variant of the measure Expected payoff of advice/delegate computed above, to test the sensitivity of the findings to a variation in the definition of search costs. In particular, we consider only the factor I (telephone and internet services) as proxying the opportunity cost of time of the investor.

It is equal to $\{\underbrace{B>=4}_{V \text { high }}, \underbrace{F>=4}_{p \text { low }}, \underbrace{\underbrace{I<=3}_{\text {low search cost }} \text { or } \underbrace{C>=4 \& E>=4}_{\text {high effort }}}_{\text {low expected control cost }}\}, 0$ otherwise.

\section{Instruments}

\section{Average regional financial literacy (from SHIW)}

This variable is average financial literacy at the regional level taken from the Bank of Italy's Survey on Household Income and Wealth (SHIW)

\section{School performance (label: SCHOOL)}

The variable is based on the question "Where were you placed as a pupil when you attended junior high school?

1: in the group of best students; 2: above the median; 3 : about at median; 4: below the median".

Our variable is constructed as a binary variable taking value 1 if the client belongs to the group 1 and 0 otherwise.

\section{General trust_1 (label: TRUST)}

TRUST: binary variable based on the answer to the following question: "Generally speaking, do you think that most people can be trusted or that you have to be very careful in dealing with people?". A value 1 is associated to the answer "I think that most people can be trusted" and a value 0 to the answer "You cannot be too careful in dealing with people".

\section{General trust_2 (label: TRUST2)}

TRUST2: variable based on the answer to the following question: "How important is for you to build trust relationships with people in everyday life?" and the answer can range from 1 (=not at all important) to 5 (=very important) 


\section{Other variables}

Wealth (label: FPATRIM)

The wealth refers to the respondent's holdings at Unicredit (2006, 30th June) and is defined in brackets (1: 10k-50k; 2: 50k-100k; 3: 100k-150k; 4: 150k-250k; 5: 250k-500k; 6: 500k-5000k). Note that the sample includes clients with a financial wealth in Unicredit at least equal to 10 thousands euros.

\section{Income (label: YL+YCF)}

This variable comprises labour and capital income perceived by the respondent's family at the end of year 2006 .

\section{Experience}

This variables captures the experience of investors in dealing with financial instruments. It is equal to the maximum experience (measured in years) attached to the three types of instruments considered, i.e., government bonds, mutual funds and stocks. 


\section{Appendix B}

\section{Additional tables}

\section{Table 6a: Demand of advice, trust and Expected payoff of advice/delegate_1}

This table reports robustness checks of the main findings reported in columns (1)-(2) of Table 4 (and Table 5). The exclusion restriction Expected payoff of advice/delegate adopted in columns (1)-(2) of Table 4 (and Table 5), is replaced here by Expected payoff of advice/delegate_1 (see Appendix A for details on the construction of the variable). Heteroskedasticity robust standard errors are reported in parentheses. ${ }^{* * *},{ }^{* *}$, and $*$ indicate significance at the 1,5 , and $10 \%$ levels, respectively.

\begin{tabular}{|c|c|c|}
\hline & $\begin{array}{l}\text { Selection } \\
\text { Hold risky assets }\end{array}$ & Advice/Delegation \\
\hline & (1) & (2) \\
\hline \multirow[t]{2}{*}{ Trust in advisor } & $0.315 \quad * * *$ & $0.144^{* * *}$ \\
\hline & $(0.065)$ & $(0.019)$ \\
\hline \multirow[t]{2}{*}{ Financial Literacy } & $0.222 \quad * * *$ & -0.017 \\
\hline & $(0.056)$ & $(0.015)$ \\
\hline \multirow[t]{2}{*}{ Self-assessed financial knowledge } & $-0.051 *$ & 0.039 \\
\hline & $(0.026)$ & $(0.032)$ \\
\hline \multirow[t]{2}{*}{ Experience } & 0.002 & -0.001 \\
\hline & $(0.002)$ & $(0.002)$ \\
\hline \multirow[t]{2}{*}{ Finance sector } & 0.092 & 0.043 \\
\hline & $(0.077)$ & $(0.152)$ \\
\hline \multirow[t]{2}{*}{ Expected payoff of advice/delegate_1 } & 0.020 & $0.062 *$ \\
\hline & $(0.031)$ & $(0.032)$ \\
\hline \multirow[t]{2}{*}{ Risk aversion } & $-0.062 \quad * * *$ & \\
\hline & $(0.015)$ & \\
\hline Demographics & yes & yes \\
\hline Income and wealth & yes & yes \\
\hline Macroarea & yes & yes \\
\hline \#obs & 1550 & 1098 \\
\hline Pseudo $\mathrm{R}^{2}$ & 0.25 & 0.12 \\
\hline \multirow[t]{2}{*}{ Instrumented endogenous regressors: } & Financial literacy & _- \\
\hline & Trust in advisor & \\
\hline Wu-Hausman test (x2(2) p-value) & 0.00 & 0.32 \\
\hline \multicolumn{3}{|l|}{ Test of instruments' validity: } \\
\hline \multicolumn{3}{|l|}{ - F-test: } \\
\hline Financial literacy & 7.86 & \\
\hline$p$-value & 0.00 & \\
\hline Trust in advisor & 11.06 & \\
\hline p-value & 0.00 & \\
\hline - Hansen-J statistic : & 0.58 & \\
\hline X2 (2) p-value & 0.75 & \\
\hline
\end{tabular}

Notes: Demographics includes age, age squared, dummy for gender, years at school, dummy for self-employment, dummy for retirement status, number of years at Unicredit Bank. Income and wealth includes the (log of) individual income and the financial wealth brackets. Macroarea considers the North-West, the North-East, the Center and the South-Islands geographical areas. Source: UCS (2007). 
Table 6b. Demand of advice, trust and Expected payoff of advice/delegate_2

This table reports robustness checks of the main findings reported in columns (1)-(2) of Table 4 (and Table 5).The exclusion restriction Expected payoff of advice/delegate adopted in columns (1)-(2) of Table 4 (and Table 5), is replaced here by Expected payoff of advice/delegate_2 (see Appendix A for details on the construction of the variable). Dependent variable and regression techniques are the same as columns (1)-(2) of Table 4 (and Table 5). Heteroskedasticity robust standard errors are reported in parentheses. $* * *, * *$, and $*$ indicate significance at the 1,5 , and $10 \%$ levels, respectively.

\begin{tabular}{|c|c|c|}
\hline & $\frac{\text { Selection }}{\text { Hold risky assets }}$ & Advice/Delegation \\
\hline & (1) & $(2)$ \\
\hline \multirow[t]{2}{*}{ Trust in advisor } & $0.323 \quad * * *$ & $0.149 * * *$ \\
\hline & $(0.064)$ & $(0.016)$ \\
\hline \multirow[t]{2}{*}{ Financial Literacy } & $0.223 \quad * * *$ & -0.019 \\
\hline & $(0.057)$ & $(0.013)$ \\
\hline \multirow[t]{2}{*}{ Self-assessed financial knowledge } & $-0.049 *$ & $0.040 *$ \\
\hline & $(0.026)$ & $(0.021)$ \\
\hline \multirow[t]{2}{*}{ Experience } & 0.002 & -0.001 \\
\hline & $(0.002)$ & $(0.002)$ \\
\hline \multirow[t]{2}{*}{ Finance sector } & 0.102 & 0.043 \\
\hline & $(0.077)$ & $(0.075)$ \\
\hline \multirow[t]{2}{*}{ Expected payoff of advice/delegate_2 } & -0.032 & $0.063 *$ \\
\hline & $(0.025)$ & $(0.034)$ \\
\hline \multirow[t]{2}{*}{ Risk aversion } & $-0.060 \quad * * *$ & \\
\hline & $(0.015)$ & \\
\hline Demographics & yes & yes \\
\hline Income and wealth & yes & yes \\
\hline Macroarea & yes & yes \\
\hline \#obs & 1550 & 1098 \\
\hline Pseudo $\mathrm{R}^{2}$ & 0.25 & 0.12 \\
\hline \multirow[t]{2}{*}{ Instrumented endogenous regressors: } & Financial literacy & - \\
\hline & Trust in advisor & \\
\hline Wu-Hausman test ( $\chi 2(2) \quad p$-value) & 0.00 & 0.38 \\
\hline \multicolumn{3}{|l|}{ Test of instruments' validity: } \\
\hline \multicolumn{3}{|l|}{$\overline{-F-t e s t:}$} \\
\hline Financial literacy & 7.74 & \\
\hline $\mathrm{p}$-value & 0.00 & \\
\hline Trust in advisor & 11.26 & \\
\hline$p$-value & 0.00 & \\
\hline - Hansen-J statistic : & 0.68 & \\
\hline$x^{2}(2) p$-value & 0.71 & \\
\hline
\end{tabular}

Notes: Demographics includes age, age squared, dummy for gender, years at school, dummy for self-employment, dummy for retirement status, number of years at Unicredit Bank. Income and wealth includes the (log of) individual income and the financial wealth brackets. Macroarea considers the North-West, the North-East, the Center and the South-Islands geographical areas. Source: UCS (2007). 
Table 6c. Demand of advice, Trust in advisor_ 1 and Expected payoff of advice/delegate

This table reports robustness checks of the main findings reported in columns (1)-(2) of Table 4 (and Table 5). The variable Trust in advisor is replaced here by its binary version, Trust in advisor_ 1. Dependent variable and regression techniques are the same as Table 4 (and Table 5). Heteroskedasticity robust standard errors are reported in parentheses. ***, **, and * indicate significance at the 1,5 , and $10 \%$ levels, respectively.

\begin{tabular}{|c|c|c|}
\hline & $\begin{array}{l}\text { Selection } \\
\text { Hold risky assets }\end{array}$ & Advice/Delegation \\
\hline & (1) & (2) \\
\hline \multirow[t]{2}{*}{ Trust in advisor_1 } & $0.833 * * *$ & $0.283^{* * *}$ \\
\hline & ( 0.166$)$ & $(0.034)$ \\
\hline \multirow[t]{2}{*}{ Financial Literacy } & $0.213 \quad * * *$ & $-0.021 *$ \\
\hline & $(0.057)$ & $(0.013)$ \\
\hline \multirow[t]{2}{*}{ Self-assessed financial knowledge } & $-0.045 *$ & $0.037 *$ \\
\hline & $(0.026)$ & $(0.021)$ \\
\hline \multirow[t]{2}{*}{ Experience } & 0.002 & -0.001 \\
\hline & $(0.002)$ & $(0.002)$ \\
\hline \multirow[t]{2}{*}{ Finance sector } & 0.054 & 0.027 \\
\hline & $(0.074)$ & $(0.072)$ \\
\hline \multirow[t]{2}{*}{ Expected payoff of advice/delegate } & $-0.056 * *$ & $0.068 * *$ \\
\hline & $(0.026)$ & $(0.033)$ \\
\hline \multirow[t]{2}{*}{ Risk aversion } & $-0.059 * * *$ & \\
\hline & $(0.015)$ & \\
\hline Demographics & yes & yes \\
\hline Income and wealth & yes & yes \\
\hline Macroarea & yes & yes \\
\hline \#obs & 1550 & 1098 \\
\hline Pseudo $\mathrm{R}^{2}$ & 0.24 & 0.12 \\
\hline \multirow[t]{2}{*}{ Instrumented endogenous regressors: } & Financial literacy & None \\
\hline & Trust in advisor & Toure \\
\hline Wu-Hausman test (x2(2) p-value) & 0.00 & 0.65 \\
\hline \multicolumn{3}{|l|}{ Test of instruments' validity: } \\
\hline \multicolumn{3}{|l|}{ - F-test: } \\
\hline Financial literacy & 7.75 & \\
\hline p-value & 0.00 & \\
\hline Trust in advisor & 7.70 & \\
\hline p-value & 0.00 & \\
\hline - Hansen-J statistic : & 0.33 & \\
\hline$\chi_{2}(2) p$-value & 0.85 & \\
\hline
\end{tabular}

Notes: Demographics includes age, age squared, dummy for gender, years at school, dummy for self-employment, dummy for retirement status, number of years at Unicredit Bank. Income and wealth includes the (log of) individual income and the financial wealth brackets. Macroarea considers the North-West, the North-East, the Center and the South-Islands geographical areas. Source: UCS (2007). 


\section{Latest CeRP Working Papers}

\begin{tabular}{|c|c|}
\hline $\mathrm{N}^{\circ} 157 / 16$ & $\begin{array}{l}\text { Riccardo Calcagno } \\
\text { Maela Giofré } \\
\text { Maria Cesira Urzì-Brancati }\end{array}$ \\
\hline $\mathrm{N}^{\circ} 156 / 16$ & $\begin{array}{l}\text { Elisa Luciano } \\
\text { Mariacristina Rossi } \\
\text { Dario Sansone }\end{array}$ \\
\hline $\mathrm{N}^{\circ} 155 / 16$ & Claudio Morana \\
\hline $\mathrm{N}^{\circ} 154 / 15$ & Vincenzo Andrietti \\
\hline $\mathrm{N}^{\circ} 153 / 15$ & $\begin{array}{l}\text { Donatella Baiardi } \\
\text { Claudio Morana }\end{array}$ \\
\hline $\mathrm{N}^{\circ} 152 / 15$ & $\begin{array}{l}\text { Ewa Gałecka-Burdziak } \\
\text { Marek Góra }\end{array}$ \\
\hline $\mathrm{N}^{\circ} 151 / 15$ & $\begin{array}{l}\text { Margherita Borella } \\
\text { Flavia Coda Moscarola }\end{array}$ \\
\hline $\mathrm{N}^{\circ} 150 / 15$ & Anna Lo Prete \\
\hline $\mathrm{N}^{\circ} 149 / 15$ & $\begin{array}{l}\text { Flavia Coda Moscarola } \\
\text { Ugo Colombino } \\
\text { Francesco Figari } \\
\text { Marilena Locatelli }\end{array}$ \\
\hline $\mathrm{N}^{\circ} 148 / 15$ & $\begin{array}{l}\text { Flavia Coda Moscarola } \\
\text { Elsa Fornero } \\
\text { Steinar Strøm }\end{array}$ \\
\hline $\mathrm{N}^{\circ} 147 / 14$ & $\begin{array}{l}\text { Matteo Morini } \\
\text { Simone Pellegrino }\end{array}$ \\
\hline $\mathrm{N}^{\circ} 146 / 14$ & $\begin{array}{l}\text { Mariacristina Rossi } \\
\text { Eva Sierminska }\end{array}$ \\
\hline $\mathrm{N}^{\circ} 145 / 14$ & $\begin{array}{l}\text { Johannes G. Hoogeveen } \\
\text { Mariacristina Rossi } \\
\text { Dario Sansone }\end{array}$ \\
\hline $\mathrm{N}^{\circ} 144 / 14$ & Elsa Fornero \\
\hline $\mathrm{N}^{\circ} 143 / 14$ & $\begin{array}{l}\text { Kees de Vaan } \\
\text { Daniele Fano } \\
\text { Herialt Mens } \\
\text { Giovanna Nicodano }\end{array}$ \\
\hline $\mathrm{N}^{\circ} 142 / 14$ & $\begin{array}{l}\text { Elisabetta Cagna } \\
\text { Giulio Casuccio }\end{array}$ \\
\hline $\mathrm{N}^{\circ} 141 / 14$ & $\begin{array}{l}\text { Massimo Baldini } \\
\text { Costanza Torricelli } \\
\text { Maria Cesira Urzì Brancat }\end{array}$ \\
\hline
\end{tabular}

To trust is good, but to control is better: How investors discipline financial advisors' activity

Financial Inclusion and Life Insurance Demand;

Evidence from Italian households

The US\$/€ exchange rate: Structural modeling and forecasting during the recent financial crises

Auto-enrollment, Matching, and Participation in 401(k) Plans

Financial deepening and income distribution inequality in the euro area

The impact of easy and early access to old-age benefits on exits from the labour market: a macro-micro analysis

The 2011 Pension Reform in Italy and its Effects on Current and Future Retirees

Labour market institutions and household consumption insurance within OECD countries

Shifting Taxes from Labour to Property. A Simulation under Labour Market Equilibrium

Absenteeism, Pension Reforms and Grandmothers

Personal Income Tax Reforms: a Genetic Algorithm Approach

Single again? Asset and portfolio changes due to widowhood shock

Drivers of performance in primary education in Togo

Economic-financial literacy and (sustainable) pension reforms: why the former is a key ingredient for the latter

A Reporting Standard for Defined Contribution Pension Plans

Equally-weighted Risk Contribution Portfolios: an empirical study using expected shortfall

Family ties: occupational responses to cope with a household income shock

The full series is available at: http://www.cerp.carloalberto.org/category/publications/working-papers/ 